\title{
Experimental analysis of wave energy converters concentrically attached on a floating offshore platform
}

\author{
M. Kamarlouei a , J.F. Gaspar a , M. Calvario a, T.S. Hallak a, M.J.G.C. Mendes ${ }^{\text {a, b }}{ }^{\text {, F. Thiebaut }}{ }^{\text {, }}$, \\ C. Guedes Soares ${ }^{\text {a, * }}$ \\ ${ }^{a}$ Centre for Marine Technology and Ocean Engineering (CENTEC), Instituto Superior Técnico, Universidade de Lisboa, Lisboa, Portugal \\ ${ }^{\mathrm{b}}$ Instituto Superior de Engenharia de Lisboa (ISEL), Instituto Politécnico de Lisboa, Lisboa, Portugal \\ ${ }^{\mathrm{c}}$ LiR - National Ocean Test Facility, MaREI Center, University College Cork, Cork, Ireland
}

\section{A R T I C L E I N F O}

\section{Article history:}

Received 1 March 2019

Received in revised form

2 January 2020

Accepted 18 January 2020

Available online 22 January 2020

\section{Keywords:}

Concentric array of wave energy converters

Floating offshore platform

Small scale prototyping

Buoy-floating platform interaction

Heave and pitch motions

\begin{abstract}
A B S T R A C T
This paper presents an initial experimental study of wave energy converters concentrically arranged and attached on a floating offshore platform model. The 1:27 scale model, has been designed, built and tested, in two main situations, without and with twelve cone shape wave energy converters. To simulate the power take-off system in each wave energy converter, rotational friction dampers have been installed on the joints of the floaters arms to the platform deck. The experimental results show that the interaction between buoys and platform have a positive effect on the platform heave and pitch motions. However, the reduction in heave and pitch motions of the platform, after installing the wave energy converter array, depends on the damping of the equivalent power take-off system. Thus, the effect of dampers in the motion of buoys is presented to allow an initial understanding of the required damping range of the power take-off system and related control strategies.
\end{abstract}

() 2020 Elsevier Ltd. All rights reserved.

\section{Introduction}

The mean annual power that is absorbed by a single point absorber wave energy converter (WEC) in a real case scenario is limited to $500 \mathrm{~kW}$ [1]. In order to maximize the wave energy absorption by these devices, they are commonly seen in arrays or wave farms. There are three different types of point energy absorber WECs that are categorized by their working principles, small bottom-referenced heaving buoy (e.g. Sea based [2]), bottomreferenced submerged heave-buoy (e.g. Ceto Buoy [3]) and floating two-body heaving converter (e.g. Wavebob [4]). There are also two different types of point absorber arrays namely, bottom-fixed and floating heave-buoy arrays. The first one is an optimized layout of heaving buoys attached to the bottom of the sea while the second is a group of WECs attached to a platform or pontoon from the bottom side (e.g. Pontoon Power Converter [5]) or upside (e. g. Wavestar [6]).

On the other hand, wave and wind energy devices are combined in hybrid semisubmersible platforms (SSPs) with the objective of

\footnotetext{
* Corresponding author.

E-mail address: c.guedes.soares@centec.tecnico.ulisboa.pt (C. Guedes Soares).
}

taking advantage of synergetic effects to reduce the levelized cost of energy (LCOE) and to increase the quality of the delivered power to the grid [7-11]. The most known hybrid SSPs concepts are the WindWaveFloat and W2Power. The recent one is the three OWC multi-use floating platform.

The WindWaveFloat project is dedicated to the integration of several different WEC devices on the WindFloat (a tri-column type SSP) [7,9]. The first WEC type is made of a spherical floater located at the center of the platform and is attached to it by three lines. The second one includes two oscillating water columns (OWC) that move within chambers created around two SSP columns (the third column supports the wind turbine (WT)). The last one consists of three oscillating surge converters (hinged rectangular flaps) assembled on the top main beams of the SSP structure.

The W2Power concept is made of two WTs, each one attached to one column of the SSP, while the WEC PTO is housed in the third column. A Pelton turbine, inside the PTO, is driven with fluid pressurized by linear arrays of point absorber WECs that are attached in each side of the platform [7,11,12].

A hybrid SSP has been also proposed with a different layout, a square shaped arrangement, of four columns. Each column supports one WT while the WECs are suspended bellow and supported by the top main beams of the structure (used to connect those 


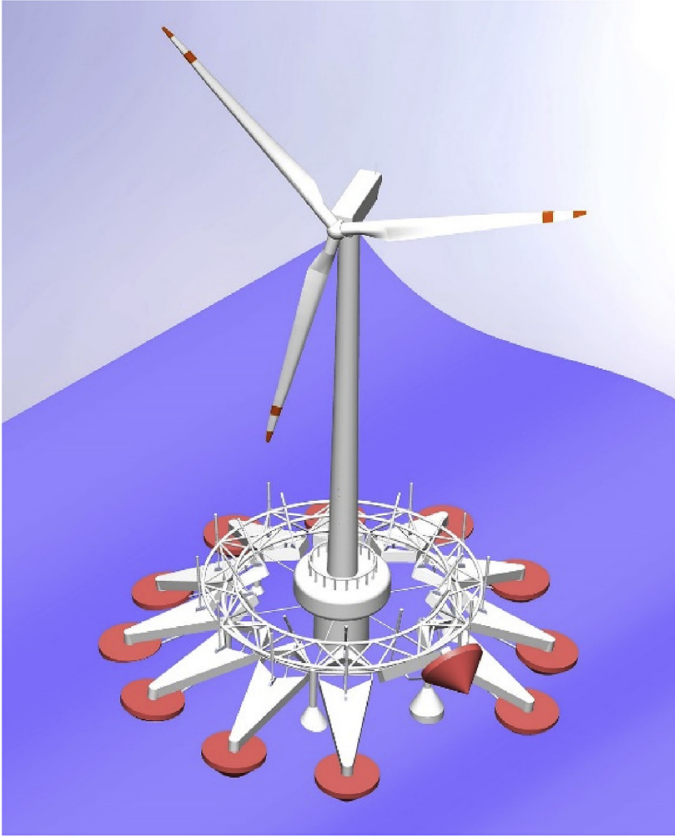

(a)

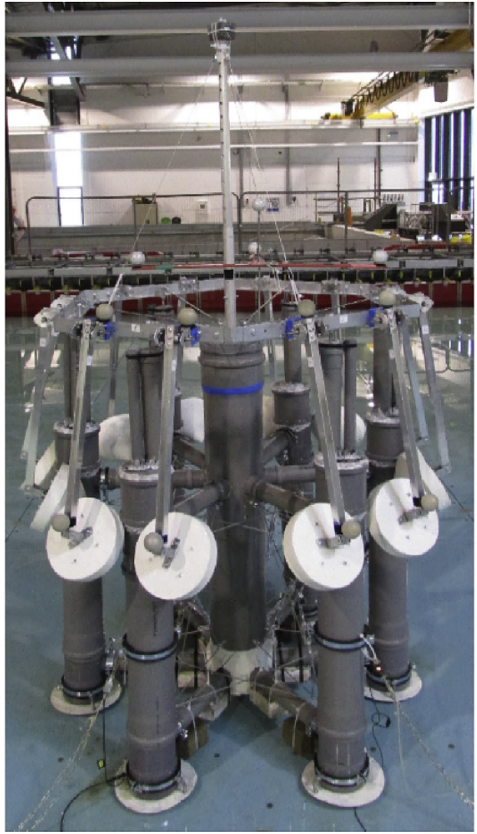

(b)

Fig. 1. Concept design (a) and model (b) of the concentric WEC array installed on floating offshore platform.

columns) [13].

In addition, the hybrid SSP concepts have been developed to improve the hydrodynamic stability, especially in case of pitching motions, feasibility, serviceability and constructability, to name a few design factors [7-12]. Pitch motions affect the WT structural integrity, because induce large external loads on the structure and reduce the fatigue life of devices. For example, a variation of five degrees in pitch leads to $50 \%$ increase of the WT blade sectional modulus to avoid failure by fatigue [14]. Therefore, reliable floating platforms must have reasonably small pitching motions.

Some studies have shown that WECs contribute to the reduction of these motions [14-19]. Zhu [8] presents a numerical study of the WEC effects on SSP floating platform. A hybrid model predictive control (MPC) method is used to reduce the platform pitching motion while maintaining the passivity of the PTOs, modelled as passive linear spring - damper systems. A method to actively control the PTOs is also presented. The numerical results have shown that the pitch motions are significantly reduced with the PTOs working as linear dampers, however they are reduced furthermore by $50 \%$ with the MPC approach (which includes stiffness and adjustable PTO counteracting forces). However the impact of these improvements on the WECs efficiency is not presented.

In the conceptual design proposed by Zhu [14], the point floater WECs are placed next to the SSP structure. Thus, they are contributing to the platform stability by generating restoring moments with their water surface areas. It is also known that SSP stability increases by spreading the water surface area, because restoring moments depend on the surface area of each column and the square of the distance between them (also increasing the second moment of area and the metacentric height of the platform). Moreover, these moments might be increased by increasing the distance between the center of gravity (COG) and the center of buoyancy (COB) [7]. Nevertheless, as Karimirad [7] points out, the main contributor to the SSP stability is the arrangement of the columns and their surface area.

There are also other solutions to control the platform pitching movements, but they consume energy instead of having the advantage of producing energy as in the WECs case. The one that has been experimentally tested in the WindFloat concept, moves water between the platform columns in order to control the inclination of the platform. However, the dynamic response may be too slow in irregular waves of a real sea state [14].

Table 1

Model variables and scale ratios.

\begin{tabular}{|c|c|c|c|c|}
\hline \multicolumn{5}{|l|}{$\lambda=\mathrm{FS} / \mathrm{M}=27$} \\
\hline Variable & Dimensions & Units & Scale Ratio & Multiplier \\
\hline Length & $\mathrm{L}$ & $\mathrm{m}$ & $\lambda$ & $2.70 \mathrm{E}+01$ \\
\hline Mass & M & $\mathrm{kg}$ & $\lambda^{3}$ & $1.97 \mathrm{E}+04$ \\
\hline Angle & None & rad & 1 & $1.00 \mathrm{E}+00$ \\
\hline Acceleration & $\mathrm{L} / \mathrm{T}^{2}$ & $\mathrm{~m} / \mathrm{s}^{2}$ & 1 & $1.00 \mathrm{E}+00$ \\
\hline Angular Acceleration & $1 / \mathrm{T}^{2}$ & $1 / s^{2}$ & $\lambda^{-1}$ & $3.70 \mathrm{E}-02$ \\
\hline Angular Velocity & $1 / \mathrm{T}$ & $1 / \mathrm{s}$ & $\sqrt{ } \lambda^{-1}$ & $1.92 \mathrm{E}-01$ \\
\hline Force & $\mathrm{M} \times \mathrm{L} / \mathrm{T}^{2}$ & $\mathrm{Kg} \times \mathrm{m} / \mathrm{s}^{2}$ & $\lambda^{3}$ & $1.97 \mathrm{E}+04$ \\
\hline Wave Height & $\mathrm{L}$ & $\mathrm{m}$ & $\lambda$ & $2.70 \mathrm{E}+01$ \\
\hline Wave Period & $\mathrm{T}$ & s & $\sqrt{\lambda}$ & $5.20 \mathrm{E}+00$ \\
\hline Velocity & $\mathrm{L} / \mathrm{T}$ & $\mathrm{m} / \mathrm{s}$ & $\sqrt{\lambda}$ & $5.20 \mathrm{E}+00$ \\
\hline Moment of Inertia & $\mathrm{M} \times \mathrm{L}^{2}$ & $\mathrm{~kg} \times \mathrm{m}^{2}$ & $\lambda^{5}$ & $1.43 \mathrm{E}+07$ \\
\hline
\end{tabular}


Table 2

Characteristics of the model.

\begin{tabular}{lll}
\hline Property & Value & Unit \\
\hline Platform & & \\
Diameter of central column & 160 & $\mathrm{~mm}$ \\
Diameter of lateral columns & 110 & $\mathrm{~mm}$ \\
Diameter of radial columns & 50 & $\mathrm{~mm}$ \\
Height & 1100 & $\mathrm{~mm}$ \\
Draft & 950 & $\mathrm{~mm}$ \\
Displacement & 70.1 & $\mathrm{~L}$ \\
Mass & 69.8 & $\mathrm{~kg}$ \\
Center of Gravity & 370 & $\mathrm{~mm}$ \\
Center of Buoyancy & 480 & $\mathrm{~mm}$ \\
Roll radius of Gyration & 638 & $\mathrm{~mm}$ \\
Pitch radius of Gyration & 637 & $\mathrm{~mm}$ \\
Yaw radius of Gyration & 362 & $\mathrm{~mm}$ \\
Height of Tower & 760 & $\mathrm{~mm}$ \\
Weight of Tower & 0.40 & $\mathrm{~kg}$ \\
Weight of Turbine & 1.10 & $\mathrm{~kg}$ \\
Buoy & & \\
Draft & 111 & $\mathrm{~mm}$ \\
Mass & 1.8 & $\mathrm{~kg}$ \\
Displacement & 1.8 & $\mathrm{~L}$ \\
Center of Gravity & 950 & $\mathrm{~mm}$ \\
Arm & & \\
Length & 400 & $\mathrm{~mm}$ \\
Mass & 0.40 & $\mathrm{~kg}$ \\
Center of Gravity & 1050 & $\mathrm{~mm}$ \\
Angle with Platform & 67.1 & $\mathrm{deg}$ \\
Angle with buoy & 22.9 & $\mathrm{deg}$ \\
\hline
\end{tabular}

Pitch and roll motions are stabilized by the action of restoring moments, and so, one possible way to increase these moments is made by increasing the distance between the surface areas and the SSP central column, as proposed by Gaspar et al. [15,16]. This is achieved by moving the WECs apart from the SSP and fixing them by long arms hinged in the main beams of the platform. These same WECs may be submerged into a localization, allowed by those long arms, where they will contribute to an increased distance between SSP COG and COB (and increased stability) while protecting them from storm conditions. Moreover, the PTOs are located far above the sea level, thus protecting them from corrosion and allowing an easier access for maintenance. The concept has been developed with numerical simulations and preliminary validated with exploratory experimental tests [17-19]. This paper presents full results and conclusions from these same tests.

In this paper, the WEC array concept and model are described in more detail in Section 2. The experimental setup and parameters including the model fixture and wave characteristics in the basin are explained in Section 3. Then in Section 4, the methodology for test and data analysis including the test plans are presented. The experimental results are presented in Section 5 and the results in different configurations are discussed in different subsections. Finally, in Section 6 the conclusion of these results is presented.

\section{Concentric WEC concept and model}

Recent numerical studies made on different arrangements of WECs $[20,21]$ have shown advantages in using WECs arranged in circular arrays. The concentric array of WECs presents much less variability on power production when compared to the rectangular ones, roughly three times lower on average [20]. The circular array (e.g. six WECs arranged in a hexagonal layout) are less sensitive to changes on the device positioning, wave direction and frequency, and may offer a more predictable power in a variable wave climate [21]. Moreover, closely spaced arrays may offer more cost effective designs despite the loss in hydrodynamic performance due to negative array interactions. Furthermore, they may contribute to

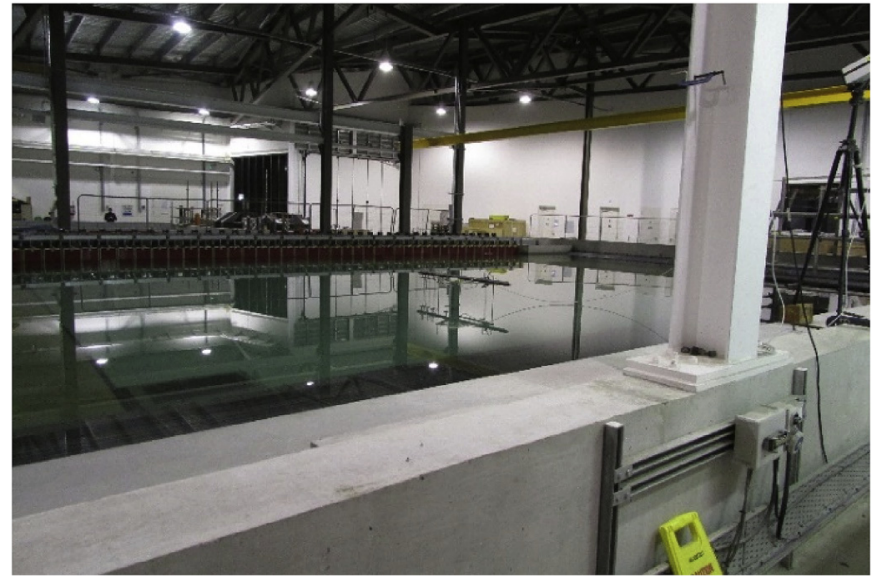

Fig. 2. The Lir NOTF ocean basin in MaREI center in Ireland, Cork.

important savings in infrastructure materials, such as steel.

In addition, studies were developed on the concentric WEC arrays however dedicated to point floater WECs made of different shapes [22,23]. The simulations indicate that a cone-cylinder floater is a better wave absorber than the hemisphere-cylinder and hemisphere floaters, because it has better hydrodynamic properties [22]. Meanwhile, the average power absorbed by coneshape floater does not contribute to a significant improve when compared to the other floater shapes. The use of these cone shaped floaters in circular arrays was also studied for a layout of 12 WECs with different diameters, and a better total extracted power was found for the larger radius of array, despite of the increasing costs in the construction and maintenance of a bigger structure [22]. The absorbed power is uniformly distributed in the circular arrangement while it is unevenly distributed in the linear and grid type arrays, where the front floaters extract more power than the rear ones, and thus, the circular array provides a better power quality (smoothness). It was as well found a uniformity in the Power TakeOff (PTO) control parameters across all floaters in a circular array. Thus, the circular array is easier to control.

On the other hand, the concentric solution is expected to bring more stability to the platform by smoothing the impact of the incident waves on the platform and increasing the water plane and ballast contributions to the restoring moment of the platform. The pitching moment, especially generated by the WT, can be counteracted by the restoring moment of buoys, which is controlled by adjusting different drafts on each conic type floater, and so, controlling their water plane areas. Thus, this solution might provide a faster and smarter reaction to changes on the platform pitch motions compared to the conventional water ballast distribution approach.

The concept, presented in Fig. 1(a), is designed according to guidelines described in Refs. [24,25] while a simplified model is designed and built with a 1:27 geometric scale (Fig. 1(b)).

According to Ref. [26], for model tests of combined platforms, the main interest is the global motion of the structure subject to the aero- and hydro-dynamic loads plus the loads from mooring and gravity. The ratio of these loads must therefore be preserved between prototype scale and model scale. Further, the loads in hydrodynamic tests in the basin are dynamic in time, thus the frequencies of the loads, and the structural frequencies must be scaled consistently. In this study, the aerodynamic forces are not modelled in the scale testing (Reynolds number is not conserved) and the Froude number is preserved for the hydrodynamic motion (Table 1). It should be indicated that, the Weber number for water 


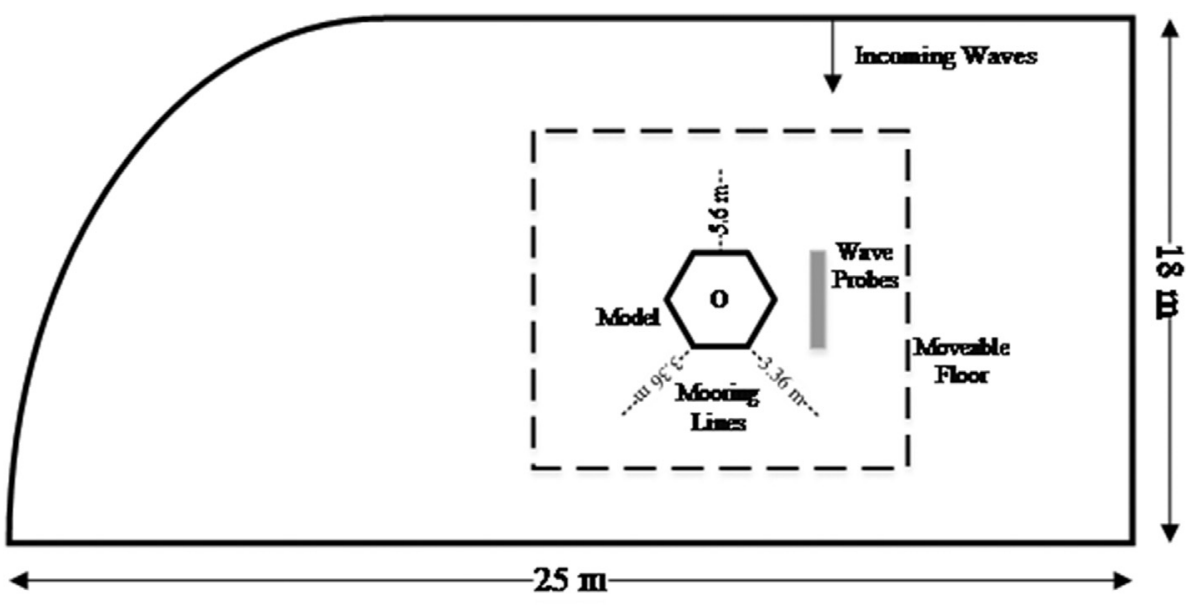

Fig. 3. The schematics of the installation of the model on the moveable floor of the basin.

surface tension and Cauchy scale for the compressibility effects are not considered due to their low practical impact in this experimental study.

Based on the scaling information in Table 1, the model was built with the specifications presented in Table 2. The weight of the model with no ballast is $31.3 \mathrm{~kg}$, but the displacement at operational draft in fresh water is $69.8 \mathrm{~kg}$. Thus, $20 \mathrm{~L}$ of ballast water is required $(18.0 \mathrm{~kg}$ distributed between the lateral columns plus $2.0 \mathrm{~kg}$ in the central column) plus $18.5 \mathrm{~kg}$ of lead in the bottom of the platform to achieve the desired draft and displacement as well as the required Center of Gravity (COG).

The prototyping process has been carried out at the mechanical workshop of Instituto Superior Técnico (IST), in Lisbon. Several materials are applied for the construction, especially PVC (main material of the hull) and steel (upper frame, heave plates, and most connections). A key element for the connection between the central column and the lateral columns is modelled in SolidWorks ${ }^{\circledR}$ and 3D-printed in Polylactic Acid (PLA) material [19]. In order to avoid leakages in underwater openings, the underwater joints and connections are internally reinforced by foam, but all the vertical columns have hollow compartments that are easier to fill with ballast water for achieving stability and draft configurations. A set of 6 damping plates made by steel sheets are installed in the bottom of each column to damp the heave motion in high sea states. Also, a wind turbine mast and nozzle with equivalent masses are installed in central column on the deck, thus the heeling moment caused by the weight of the wind turbine is fairly represented. The hexagonal

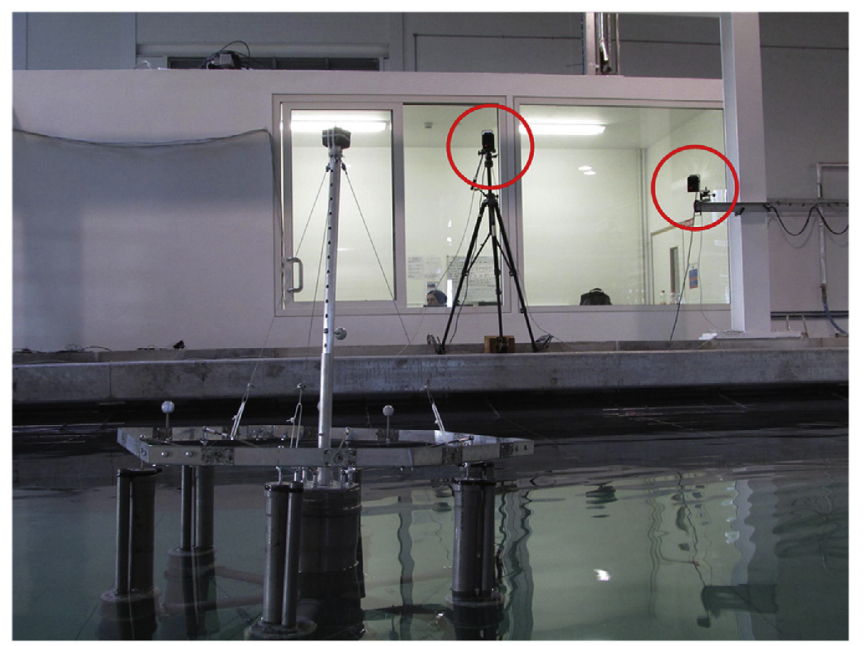

Fig. 4. Qualisys motion camera system installed in the edge of the wave basin.

steel frame used as the deck of the platform include connections for 12-point absorber WECs via aluminum arms.

Moreover, a set of 12 dampers are installed in the hinge connection of the arm to the hexagonal deck. The dampers used as the PTO system are friction dampers (part number: FFD-25-FS-L502) with maximum rotational speed of $30 \mathrm{rpm}$ [27]. They are

Table 3

The regular and irregular wave characteristics.

\begin{tabular}{|c|c|c|c|}
\hline \multicolumn{4}{|l|}{ Regular Waves } \\
\hline Wave Amp. (cm) & Wave Period (s) & & Duration (s) \\
\hline $\begin{array}{l}1.00 \\
2.00 \\
4.00\end{array}$ & $\begin{array}{l}0.6,0.8, \ldots, 4.0 \\
0.6,0.8, \ldots, 4.0 \\
0.6,0.8, \ldots, 4.0\end{array}$ & & 128 \\
\hline \multicolumn{4}{|l|}{ Irregular Waves } \\
\hline Sea State & Hs (cm) & $\mathbf{T p}(\mathbf{s})$ & Duration (s) \\
\hline $\begin{array}{l}1 \\
2 \\
3 \\
4 \\
5 \\
6 \\
7\end{array}$ & $\begin{array}{l}2.78 \\
4.63 \\
6.48 \\
8.33 \\
10.18 \\
12.04 \\
13.89\end{array}$ & $\begin{array}{l}1.05 \\
1.15 \\
1.27 \\
1.39 \\
1.50 \\
1.59 \\
1.70\end{array}$ & 240 \\
\hline
\end{tabular}




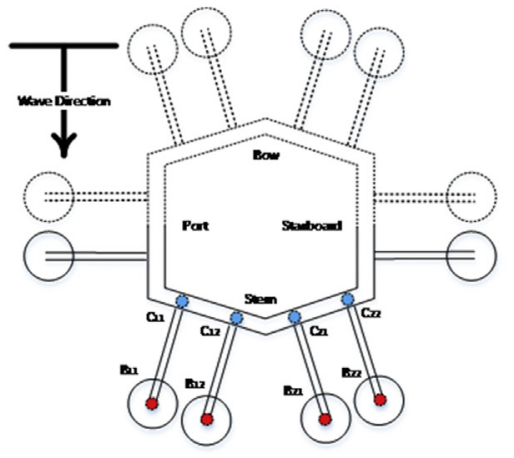

(a)

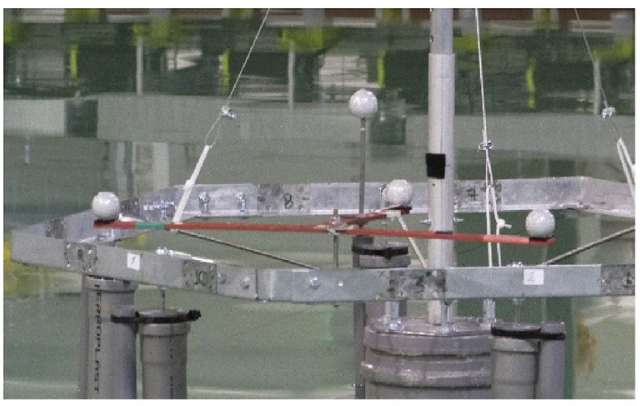

(b)

Fig. 5. The XY plane of the WEC array attached to the hexagonal deck (a) and motion camera tags on T-section installed in the stern side of the platform (b).

unidirectional and acting only counterclockwise while their maximum supported damping torque is $50 \mathrm{Ncm}$.

\section{Experimental setup}

In this study, the designed WEC layout is tested in a MaRINET2 project during two weeks at the Center of Marine and Renewable Energy (MaREI center), Lir National Ocean Test Facility. It should be indicated that the model is designed for fast assembly, detachment, and easy transportation. The next step after model assembly is the leakage test that is done in dry and wet conditions. In dry condition all ballast tanks are filled with water outside the basin to see if all the tanks are waterproof. Then in the wet condition, the platform is transported to the basin and remain there for half a day to monitor the changes in waterline. Then after the stability tests and weight balance of the platform, the necessary instruments for capturing

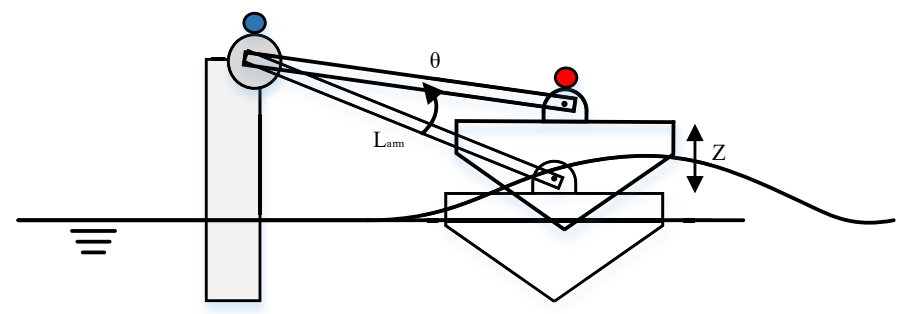

(a)

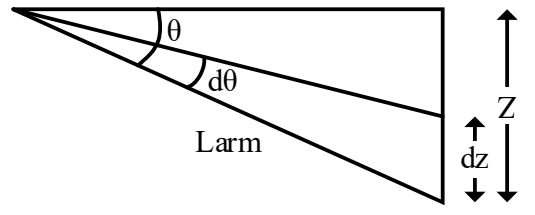

(b)

Fig. 6. Transformation of the vertical heave motion of the buoy to rotational motion of the damper (a) and the relation between the linear and angular motions (b).

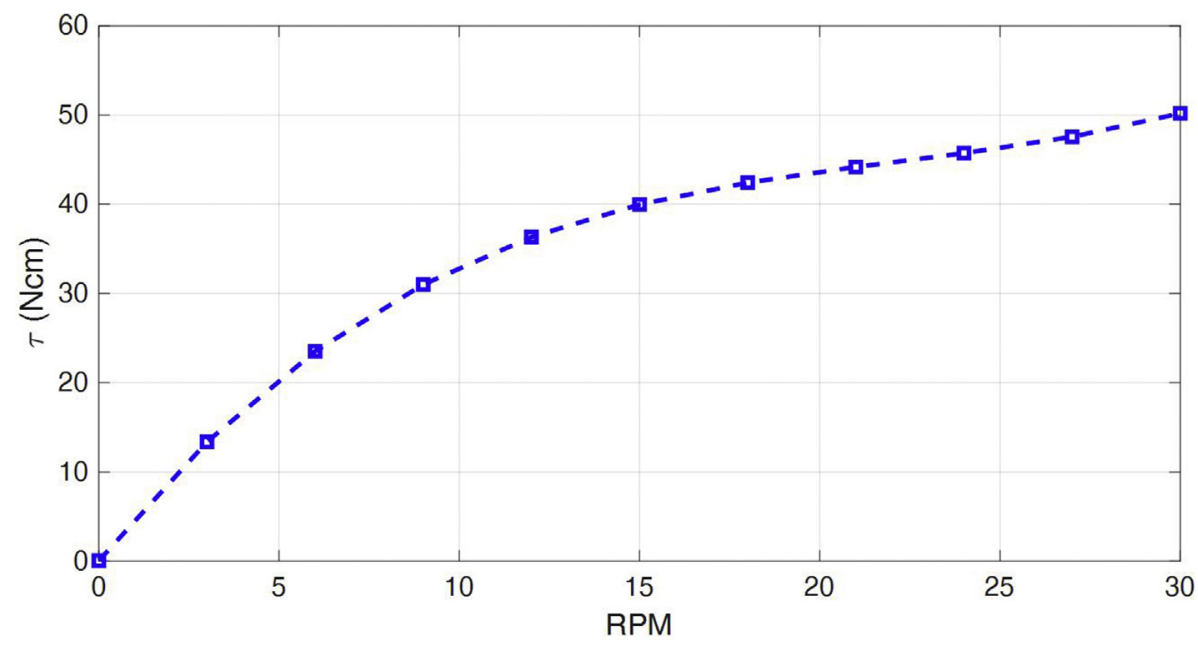

Fig. 7. Damping moments of the rotational damper in various rotational velocities. 
Table 4

Defined test cases, scenarios, and considerations.

\begin{tabular}{|c|c|c|c|c|}
\hline & Test case & Scenarios & Tests & Details \\
\hline \multirow[t]{10}{*}{ Floating Platform } & Without WECS & Without mooring & Free decay test & Roll, Pitch, Heave \\
\hline & & With mooring & Free decay test & $6 \mathrm{DoF}$ \\
\hline & & & Regular wave test & $\mathrm{H}=1,2,4 \mathrm{~cm} \& \mathrm{~T}=0.6-4.0 \mathrm{~s}$ \\
\hline & & & Irregular wave test & Sea states $1-7$ (Table 3 ) \\
\hline & With WECs & Without dampers & Free decay test & $6 \mathrm{DoF}$ \\
\hline & & & Regular wave test & $\begin{array}{l}\mathrm{H}=1 \mathrm{~cm} \mathrm{\&} \mathrm{T}=0.6-4.0 \mathrm{~s} \\
\mathrm{H}=2,4 \mathrm{~cm} \mathrm{\&} \mathrm{T}=1.4 \mathrm{~s}\end{array}$ \\
\hline & & & Irregular wave test & Sea state $2-7$ (Table 3 ) \\
\hline & & With dampers & Free decay test & $6 \mathrm{DoF}$ \\
\hline & & & Regular wave test & $\begin{array}{l}\mathrm{H}=1 \mathrm{~cm} \mathrm{\&} \mathrm{T}=0.6-4.0 \mathrm{~s} \\
\mathrm{H}=2,4 \mathrm{~cm} \& \mathrm{~T}=1.4 \mathrm{~s}\end{array}$ \\
\hline & & & Irregular wave test & Sea state $2-7$ (see Table 3 ) \\
\hline
\end{tabular}

motions and loads are installed on the platform.

The experiments are performed in the medium size ocean basin of the Lir NOTF facility. The basin is $25 \mathrm{~m} \times 17 \mathrm{~m}$ and $1 \mathrm{~m}$ deep with a moveable floor, which increases the depth up to $2.5 \mathrm{~m}$ (Fig. 2). The wave paddles can generate real and simulated waves with the peak wave capacity of $\mathrm{H}_{\mathrm{s}}=0.16 \mathrm{~m}, \mathrm{~T}_{\mathrm{p}}=1.4 \mathrm{~s}$ and $\mathrm{H}_{\max }=0.32 \mathrm{~m}$, which is suitable for small scale operational conditions up to 1:50. Also, active and passive wave absorption shores are present all around the basin in order to allow improved wave conditions and shorter settling times.

In Fig. 3 the model installation in the wave basin can be seen in detail. The model is set in the middle of the basin with a catenary mooring system with three lines. The length of mooring line in the bow side is $5.6 \mathrm{~m}$ and the ones in the stern, port and starboard sides, are $3.36 \mathrm{~m}$. Moreover, the mooring system is made of steel chains, without springs and dampers, with specific weight of $0.0713 \mathrm{~kg} / \mathrm{m}$ and mainly used for soft station keeping, i.e. avoiding excessive surge, sway, and yaw motions. One load cell is added in each mooring line for measuring the mooring forces.

Experiments are performed for unidirectional regular and irregular waves. Different waves are generated by the wavemaker using the available software packages in the laboratory. The Pierson Moskowitz wave spectrum is applied for generating the random wave signal. Two main factors used in wave generation are significant wave height $\left(\mathrm{H}_{\mathrm{m} 0}\right)$ and the peak period $\left(\mathrm{T}_{\mathrm{p}}\right)$ that are scaled before being used in the tests according to Refs. [28,29]. Table 3 shows the simulated regular and irregular waves. The regular waves are simulated in 1,2 and $4 \mathrm{~cm}$ wave heights and various periods from 0.6 to $4.0 \mathrm{~s}$. For time-saving purposes, in some cases, the regular wave tests in the wave amplitude of 2 and $4 \mathrm{~cm}$ are performed in one wave period $(\mathrm{T}=1.4 \mathrm{~s})$. The irregular waves are simulated in 7 different sea states. The average lifetime of each sea state in the offshore region is $20 \mathrm{~min}$. Thus, by considering the scaling factor of this test $(1 / 27)$, the duration of each irregular wave test is $4 \mathrm{~min}(240 \mathrm{~s})$.

To calibrate the wave makers and monitor the generated waves, three wave gauges are installed $1 \mathrm{~m}$ away in the starboard side of the model (see Fig. 3). These wave gauges are installed in parallel with buoys in the bow side, the central column of the model, and buoys in the stern side, respectively.

\section{Methodology}

To capture the motion of the platform, the six degrees of freedom Qualisys motion camera system shown in Fig. 4 is used. In this case, the position is accurately determined, and acceleration is calculated (easier to derive and integrate comparing with inertial measuring sensors). The optical motion cameras capture the motion of tags installed on the structure. The cameras are placed in the stern side of the platform and four tags, starboard, port, stern and top, are installed on a T-section attached to the stern side of the deck, after a careful analysis of the model hydrostatic data, and positioning of the platform center of gravity. The latter is a critical parameter for the platform acceleration calculations.

On the other hand, to monitor the heave motion of buoys attached to the platform, more tags are installed on the deck and four buoys in the stern side of the platform. As shown in Fig. 5(a), the wave direction is zero-angle (head sea condition). The blue circles in Fig. 5(a) are indicating the localization of the tags for measuring the movements of the platform deck and the red ones for monitoring the movements of buoys. The buoy tags are named as $B_{11}, B_{12}, B_{21}, B_{22}$ and their associated tags on the deck as $C_{11}, C_{12}$, $C_{21}$, and $C_{22}$, respectively from port to starboard. The T-section and mentioned camera tags for monitoring the movements of the platform in 6 DoF are presented in Fig. 5(b).

The motions captured by the Qualisys system are then used to determine the motions of the arm. It should be indicated that the relative movements of buoys and deck are used for calculation of angular displacement and velocity of the arm as well as the damping moment of the equivalent PTO system. In order to measure the angular displacement and velocity of each arm, two data sets are required, motions of buoys $\left(B_{i j}\right)$ and deck $\left(C_{i j}\right)$. Fig. 6(a) presents the movements of the buoy and arm in waves, where $Z$ is the relative vertical displacement of the $B_{i j}$ in respect to the $C_{i j}$ and $\theta$ is the relative angular displacement of the arm (with the length of $\left.L_{\text {arm }}\right)$. Also, Fig. 6(b) shows the relative vertical $(d z)$ and angular $(\theta)$ displacements of the arm including their initial values calculated by calm water tests, $Z$ and $\theta_{0}$, respectively. The exact value of the $L_{a r m}$, the effective length of the arm between two joints, is determined by using $\theta_{0}$ and measuring horizontal distance between $B_{i j}$ and $C_{i j}$ in calm water.

The vertical movements of the buoy are translated into rotational movements of the arm with:

$\theta=\theta_{0}-\sin ^{-1}\left(\frac{Z-d z}{L_{a r m}}\right)$

Then, the time series of $\theta$ is used to calculate the rotational velocity of the $\operatorname{arm}(\dot{\theta})$. As shown in Fig. 7, damping moments of the rotational damper $(\tau)$ is a third order polynomial function of $\dot{\theta}$ (in RPM) [27]:

$$
\tau(t)=0.003 \times \dot{\theta}(t)^{3}-0.202 \times \dot{\theta}(t)^{2}+5.019 \times \dot{\theta}(t)+0.050
$$

Tests were performed in calm water, regular and irregular waves (presented in Table 3) to understand the hydrostatic and hydrodynamic behavior of the floating offshore WEC array. Moreover, all the experiments were performed in presence of a mast-and-nozzle 


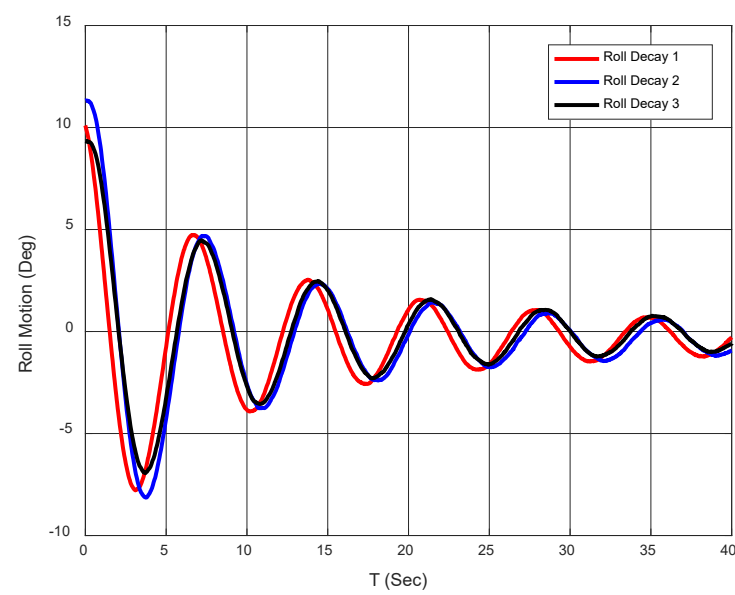

(a)

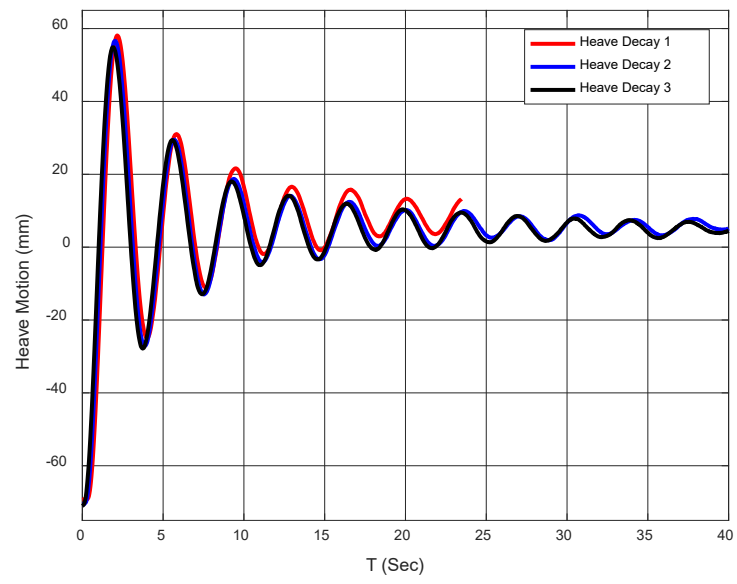

(c)

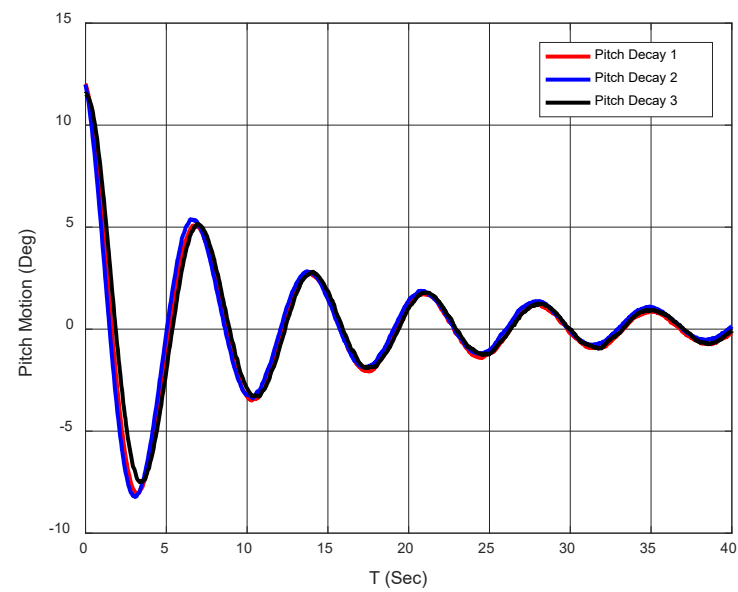

(b)

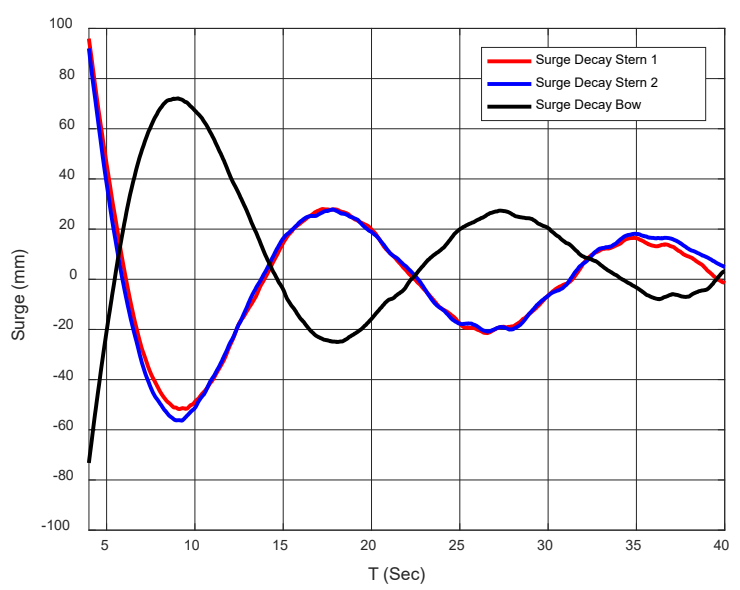

(d)

Fig. 8. The free decay tests of the floating platform in roll (a), pitch (b), heave (c), and surge (d).

Table 5

Free decay test results for different floating platform cases.

\begin{tabular}{lcc}
\hline DoF & Model Eigen Period (s) & Full Scale Eigen Period (s) \\
\hline \multicolumn{3}{c}{ without WECs and moorings } \\
\hline Heave & 3.66 & 36.01 \\
Roll & 7.06 & 36.48 \\
Pitch & 7.03 & 18.52 \\
\hline \multicolumn{3}{c}{ without WECs and with moorings } \\
\hline Heave & 3.57 & 32.64 \\
Roll & 6.29 & 31.71 \\
Pitch & 6.11 & 17.90 \\
\hline \multicolumn{3}{c}{18.21} \\
\hline Heave & with WECs, moorings and dampers \\
Roll & 3.45 & 21.12 \\
Pitch & 3.51 & \\
\hline
\end{tabular}

on the center of the platform to simulate a possible hybrid windwave energy converter. The weight of the mast and nozzle amounts to a $250 \mathrm{~kW}$ turbine scaled down, though the thrust force on the turbine is not simulated. Based on the defined objectives, two test cases with different scenarios are planned (Table 4) to study the following metrics in the WEC array model:
- The motion amplitude of platform and WECs in various waves. - The effect of WEC array on the motion of the platform.

- The effect of dampers on the motion of buoys.

As indicated in Table 4, the study on the motion of the floating platform is performed in two different test cases, "Without WECs" and "With WECs". As seen in the title of the test cases, the difference between them is the WEC layout that is added in the second case. In the first case, two scenarios are tested, without and with mooring system. Also, the second case is tested in two scenarios, without and with dampers. A comparison between different test cases and scenarios can clarify the effects of different elements on the motion of the floating platform.

The first scenario of the first case is only concerned about the free decay test of the platform, while in the second scenario, the platform is tested in regular and irregular waves as well. Meanwhile, the second test case is tested in two scenarios, WECs without dampers and WECs with rotational dampers attached to the joints. In the first scenario, 12 buoys are freely hinged to the deck of the platform through the arm while in the second scenario one damper is added to the hinge connections of the arm and deck.

The experiments start with free decay tests to find the eigen periods of the oscillatory DoFs in free floating condition. Then, this test is carried out for all moored scenarios. The free decay tests are 

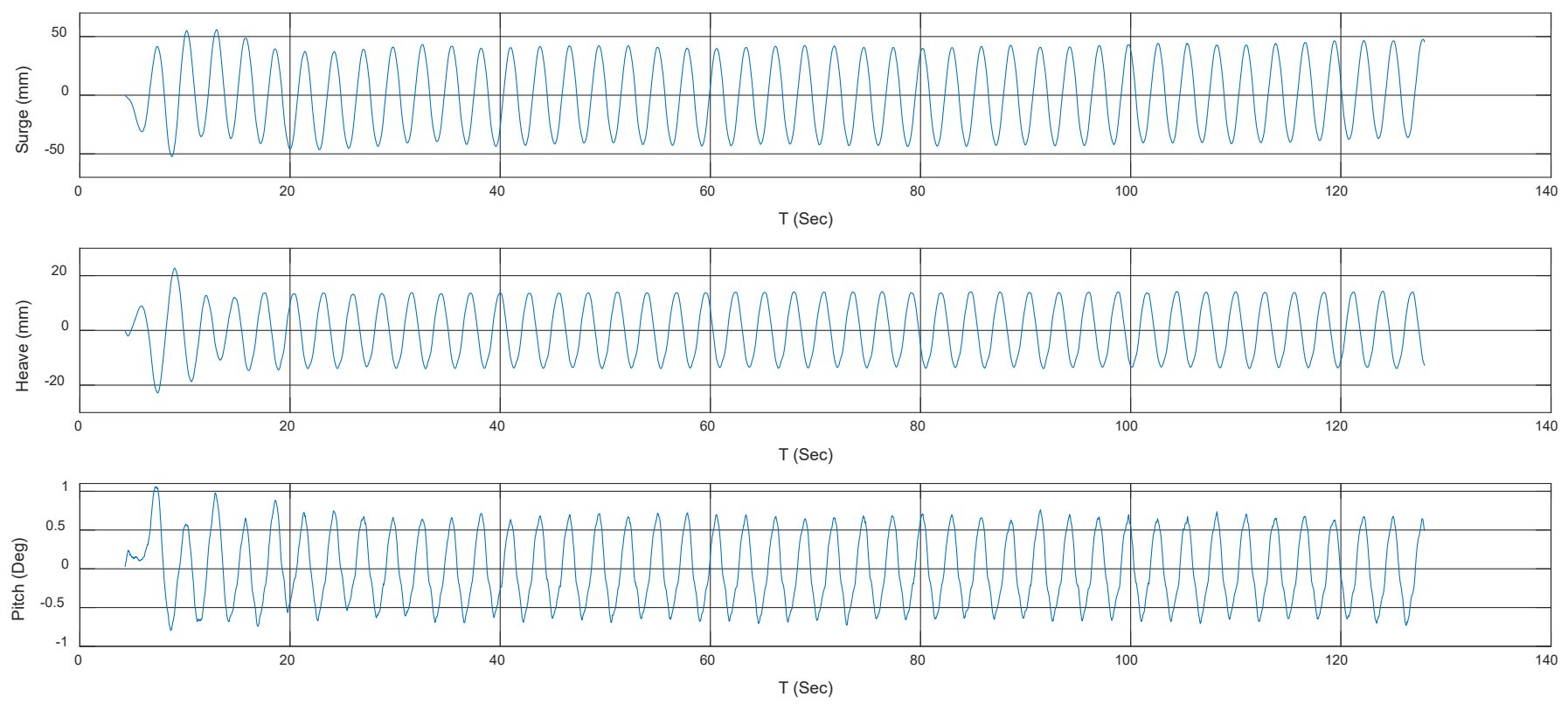

Fig. 9. Response amplitudes of surge, heave and pitch motion of the platform in "without WEC" case in regular wave with $\mathrm{H}=4 \mathrm{~cm}$ and $\mathrm{T}=2.8 \mathrm{~s}$.

repeated three times to reduce the effects of the uncertainties induced by human factors in the test (the inclining moments are made manually). It should be indicated that, an automated procedure [30] is applied for free decay result processing.

The main objective of the regular wave tests is to determine the time series of motion responses of the platform and calculate the response amplitude operations (RAOs) of each test case in different scenarios. Motion RAOs can be measured as the response amplitude of that motion divided by the amplitude of the incident regular wave. This study clarifies the effects of elements on the hydrodynamic of each test case.

One of the outputs of the irregular wave test is the response spectrum of various motions showing the distribution of energy in various frequencies. Moreover, the variance of displacement, velocity and acceleration for various motions can be extracted from this spectrum. These variances are determined with:

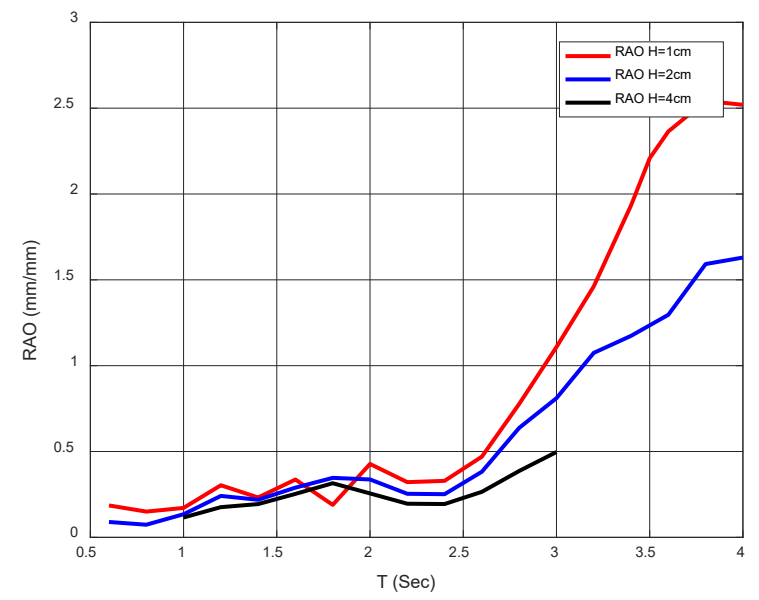

(a)

$$
\begin{aligned}
& m_{0}=\int_{0}^{\omega} S(\omega) d \omega \\
& m_{2}=\int_{0}^{\omega} \omega^{2} S(\omega) d \omega \\
& m_{4}=\int_{0}^{\omega} \omega^{4} S(\omega) d \omega
\end{aligned}
$$

where $S(\omega)$ is the variance spectrum and $\omega$ is the wave frequency in $\mathrm{rad} / \mathrm{s}$. In order to assess the amplitude of motion of the platform

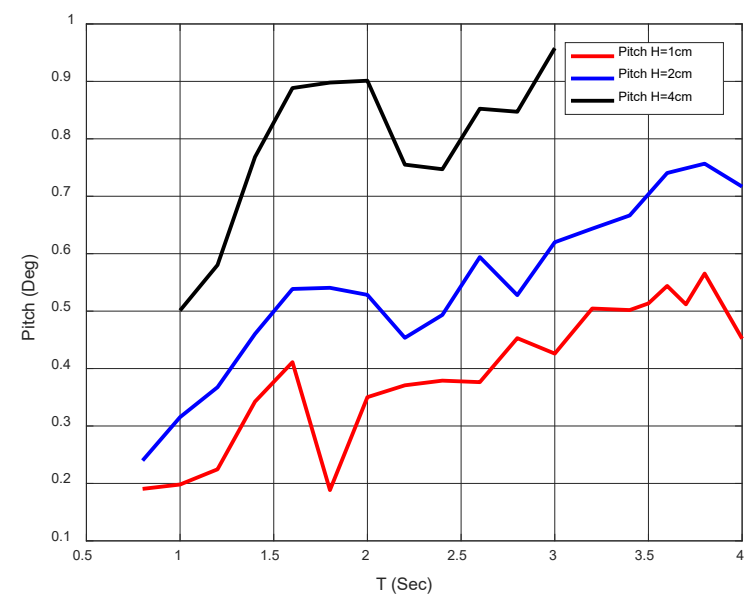

(b)

Fig. 10. RAO of heave and pitch motion of the platform in "without WEC" case. 

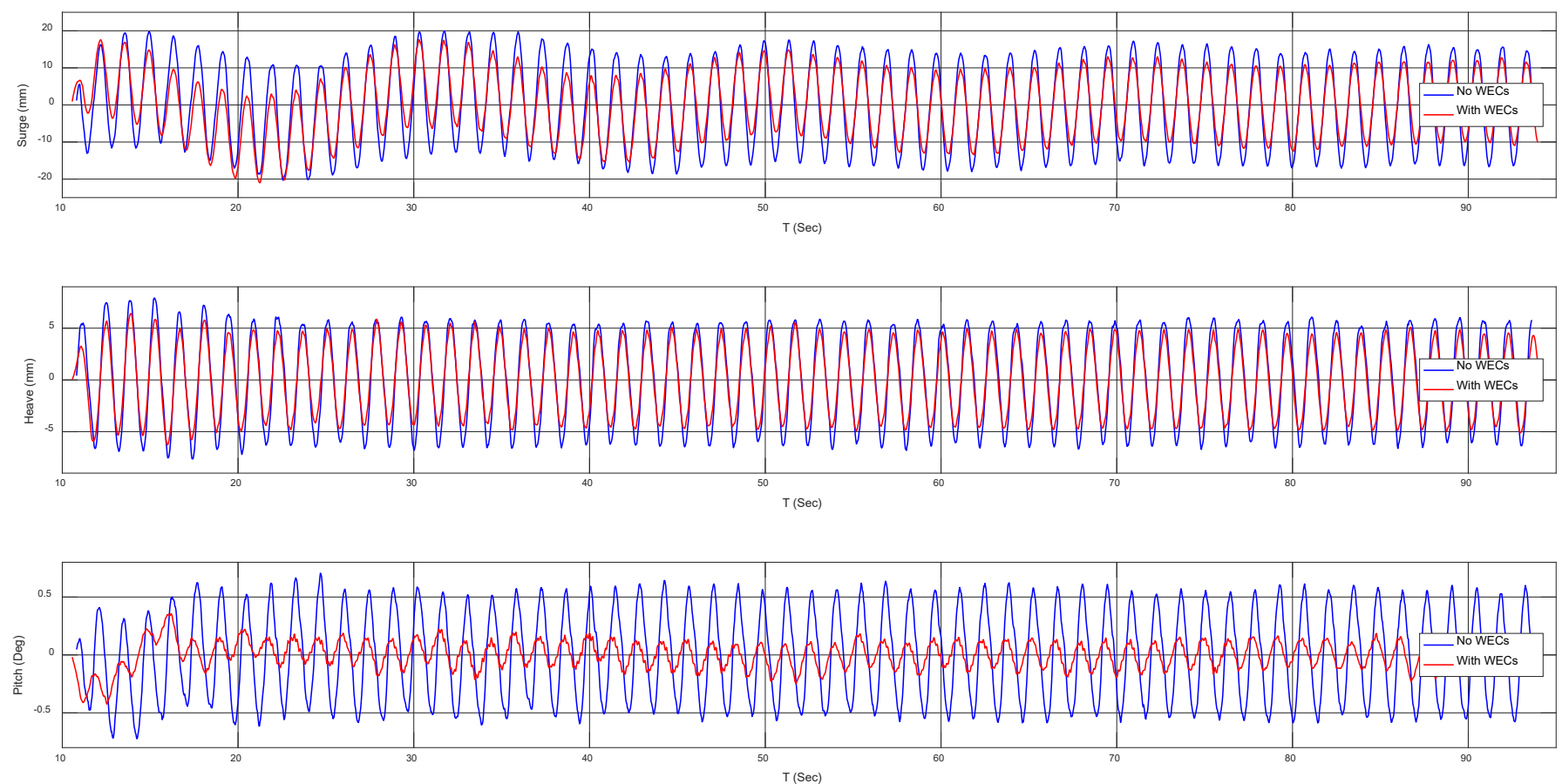

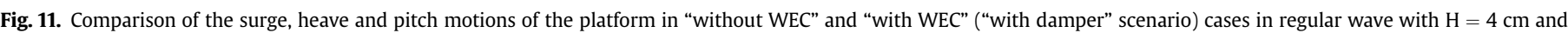
$\mathrm{T}=1.4 \mathrm{~s}$.

and WECs in each situation, the significant amplitude of motions is calculated based on two different methods. In the first method, the significant amplitude is defined as the average of one-third of highest amplitude of motion. In this regard, the amplitude of each single response is measured and then sorted from the highest to lowest and the average of one-third of highest values are calculated as significant amplitude of motion. In the second method, the significant amplitude of motion is calculated by $2 \sqrt{m_{0}}$, thus the values should match if the simulated sea is well represented by a zeromean Gaussian process with narrow-banded spectrum. The values may also be compared to the numerical values, i.e. obtained via crossing the RAOs with the incoming sea spectrum.

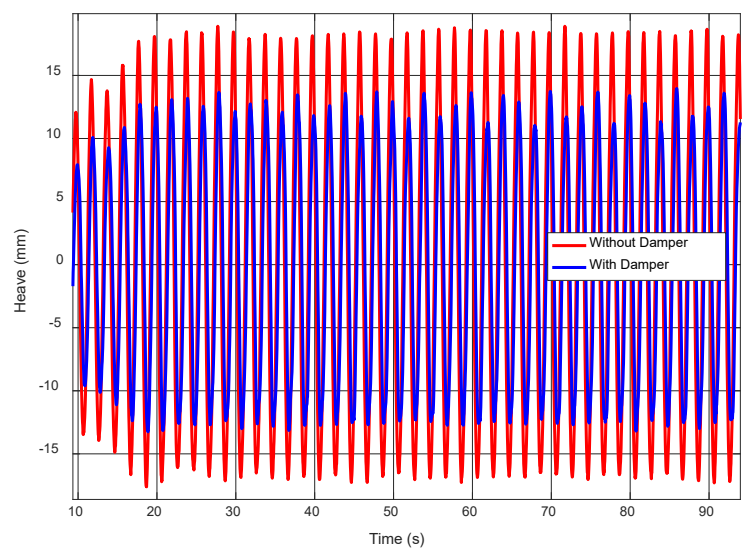

(a)

\section{Results and discussion}

In this section, the results of the tests presented in Table 4 are discussed in detail. The results are categorized in three main sections, free decay, regular, and irregular wave tests to provide a better understanding of all results.

\subsection{Free decay test}

Free decay tests are performed for all scenarios of both test cases presented in Table 4. In the scenario without mooring (of without WEC test case), the tests are only performed in heave, roll and pitch

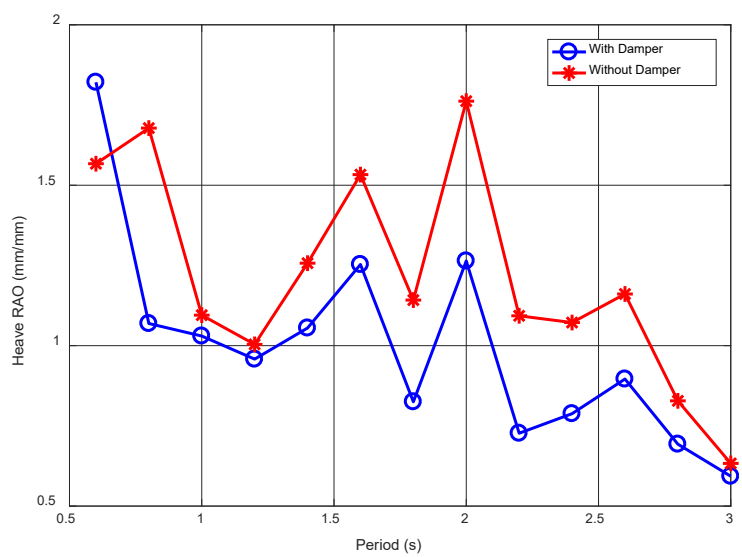

(b)

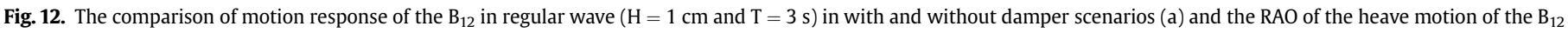
in various wave periods (b). 

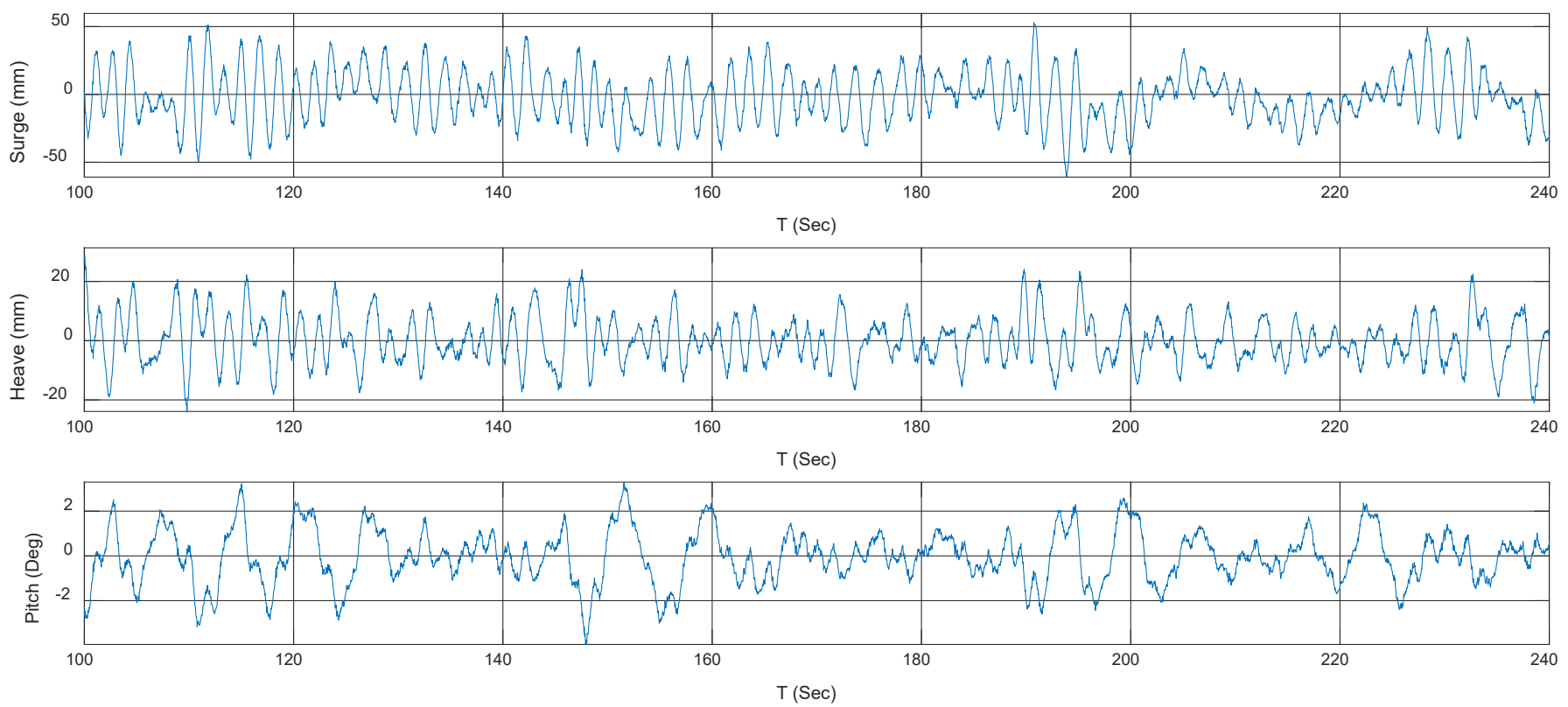

Fig. 13. Motion response of the platform in "without WEC" case - irregular waves in sea state 6 .

motions because the platform is not moored and there are no restrictions in other DoFs. Fig. 8(a)-(c) show the results of the free decay test in without mooring situation.

As presented in Fig. 8(a) and (b), the amplitude of roll and pitch as well as their eigen periods are identical, because the underwater part of the platform is symmetric in XY plan. Fig. 8(c) shows the heave decay test result in without mooring situation and Fig. 8(d) shows the surge decay test results in with mooring scenario of the

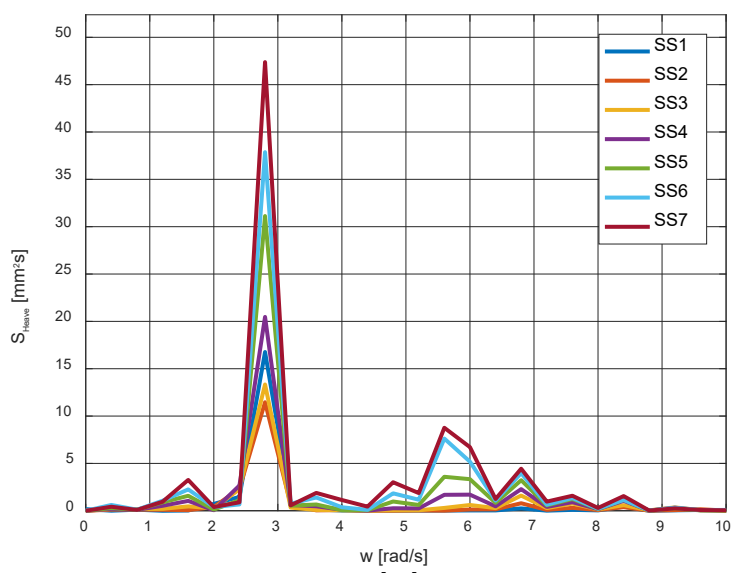

(a)

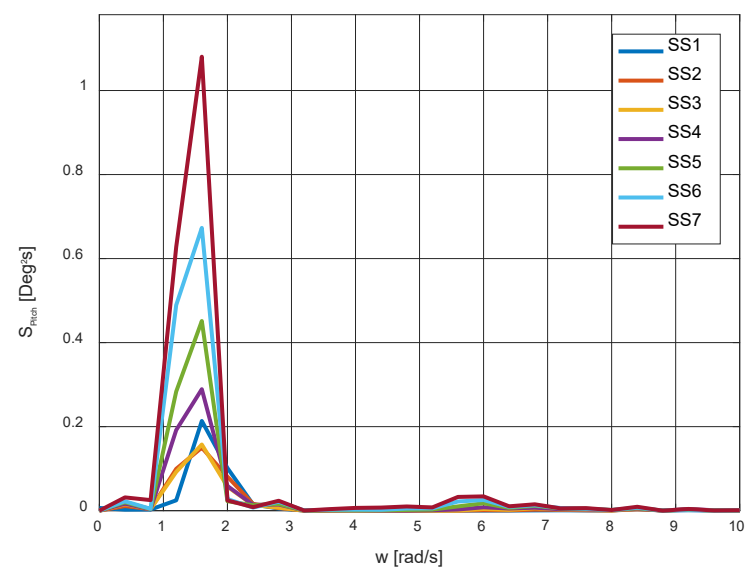

(b)

Fig. 14. The heave (a) and pitch (b) response spectrums of the platform in "without WEC" case in different sea states.

Table 6

Significant amplitude of the platforms' heave and pitch motions in "without WEC" case.

\begin{tabular}{|c|c|c|c|c|c|c|}
\hline \multirow[t]{2}{*}{ Sea states } & \multicolumn{3}{|c|}{ Heave (mm) } & \multicolumn{3}{|l|}{$\operatorname{Pitch}\left({ }^{\circ}\right)$} \\
\hline & Method 1 & Method 2 & Numerical & Method 1 & Method 2 & Numerical \\
\hline 1 & 4.41 & 0.96 & 2.523 & 0.73 & 1.35 & 1.565 \\
\hline 2 & 5.24 & 3.86 & 4.479 & 0.79 & 2.06 & 2.782 \\
\hline 3 & 6.82 & 3.75 & 6.450 & 0.79 & 1.82 & 4.107 \\
\hline 4 & 8.42 & 4.10 & 8.343 & 1.24 & 2.37 & 5.476 \\
\hline 5 & 9.99 & 4.20 & 10.63 & 1.18 & 1.95 & 6.864 \\
\hline 6 & 12.34 & 8.27 & 14.13 & 1.31 & 2.10 & 8.262 \\
\hline 7 & 14.39 & 9.82 & 21.24 & 1.57 & 2.39 & 9.752 \\
\hline
\end{tabular}


Table 7

Significant amplitude of motions in the "with WEC" scenario and comparison with "without WECs" scenario.

\begin{tabular}{lllll}
\hline Sea states & Heave $(\mathrm{mm})$ & Reduction $(\%)$ & Pitch $\left({ }^{\circ}\right)$ & Reduction $(\%)$ \\
\hline 2 & 5.49 & $-4.77^{\mathrm{a}}$ & 0.75 & 5.06 \\
3 & 6.25 & 8.35 & 0.76 & 3.80 \\
4 & 7.02 & 16.62 & 0.81 & 34.67 \\
5 & 8.42 & 15.71 & 0.93 & 21.18 \\
6 & 9.97 & 19.20 & 0.96 & 26.71 \\
7 & 11.91 & 17.23 & 1.02 & 35.03 \\
\hline
\end{tabular}

a The only case that the heave amplitude of the platform is increased in "with WEC" case.

first case. To compare the eigen periods of different test cases and important scenarios, the results of the three free decay tests are presented in Table 5.

As revealed by Table 5, the mooring system and WECs have considerable effects on the eigen period of heave. The mooring
Table 8

Significant amplitude of heave of the $\mathrm{B}_{12}$ in irregular waves.

\begin{tabular}{lll}
\hline Sea States & Heave $(\mathrm{mm})$ & \\
\cline { 2 - 3 } & without damper & with damper \\
\hline 2 & 31.40 & 26.47 \\
3 & 37.25 & 30.63 \\
4 & 44.33 & 35.91 \\
5 & 51.20 & 40.25 \\
6 & 58.62 & 46.38 \\
7 & 66.43 & 53.19 \\
\hline
\end{tabular}

system reduces the eigen period of the platform by $2 \%$ compared to the platform without mooring system, while adding WEC array to the platform ("with dampers" scenario) decreases the heave eigen period by $6 \%$. The effects of mooring and WECs are more considerable in case of roll and pitch motion by around 13\%. The main reasons for these differences are the restoring forces of the mooring

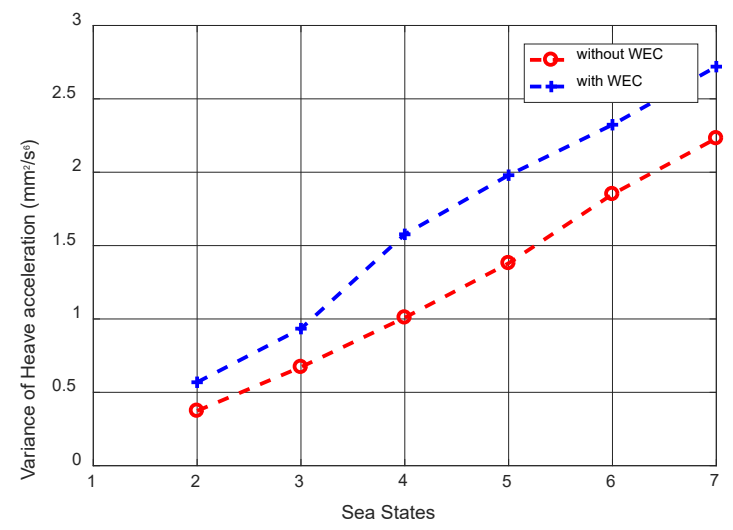

(a)

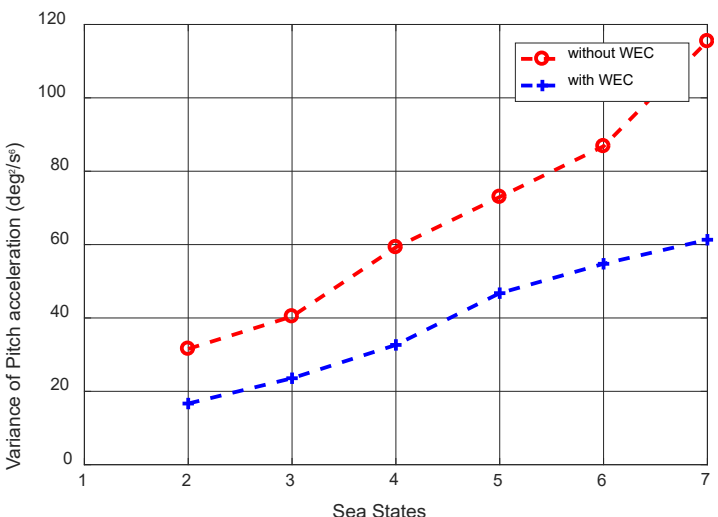

(b)

Fig. 15. Variance of heave (a) and pitch (b) accelerations in "without WEC" and "with WEC" ("with damper" scenario) cases.

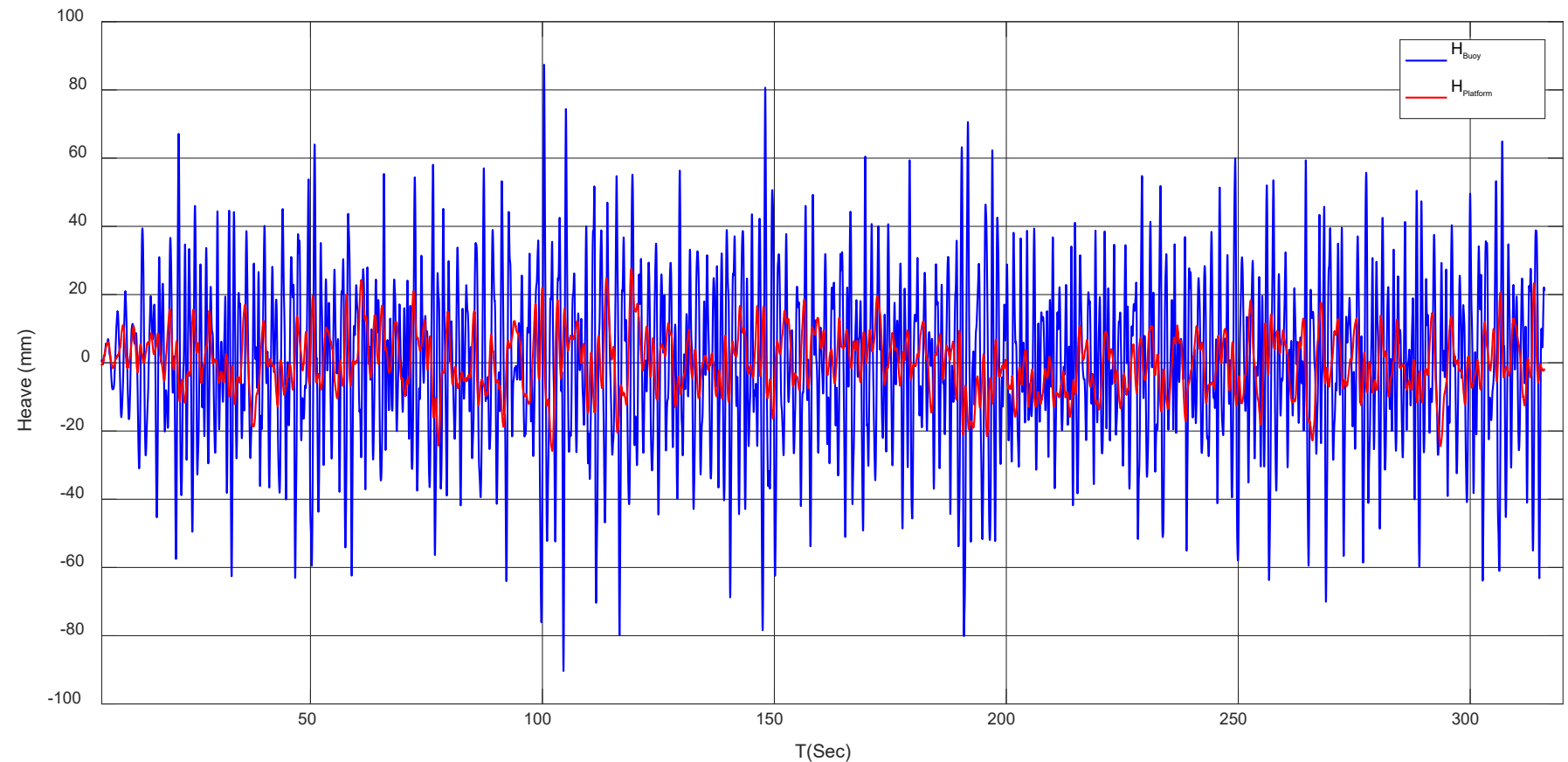

Fig. 16. Heave response of the $B_{12}$ and $C_{12}$ after installation of damper in the hinge connection of arm and deck. 
system. The change in displacement and center of gravity that moved upward after installation of WECs is responsible for the further decrease of eigen periods. Also, the effect of restoring damping generated by dampers is considerable in the final situation. Due to the lack of restoring moment, the outputs of free decay test of "without damper" scenario are not satisfying, and they are not presented in Table 5.

\subsection{Regular wave tests}

According to Table 4, regular wave tests of the floating platform are performed in two test cases. Fig. 9 shows the surge, heave, and pitch amplitudes of the platform in regular wave with $\mathrm{H}=4 \mathrm{~cm}$ and $\mathrm{T}=2.8 \mathrm{~s}$, in with mooring scenario (of "without WEC" test case).

Fig. 10(a) shows the heave RAO of the platform in the case "without WEC". In $\mathrm{H}=4 \mathrm{~cm}$, the tests are done in a period range up to $3 \mathrm{~s}$. As shown in this figure, there is an obvious nonlinearity in heave motion that is mainly due to nonlinear viscous damping related to the elements that cross the free surface and other small elements underwater. Moreover, the model is built quite compact with a considerable number of joints and elements underwater. As expected, the amplitude of the response does not increase linearly with the amplitude of the incoming wave, but it follows a weaker trend. For instance, heave's peak of response (Fig. 10(a)) drops almost by $50 \%$ from $1.0 \mathrm{~cm}$ to $2.0 \mathrm{~cm}$ wave amplitude. Fig. 10(b) shows that the pitch amplitude of the platform increases by the wave amplitude.

In addition, a comparison is made between the cases "without WEC" and "with WEC", considering the scenario "with damper" in the latter case. Fig. 11 shows the surge, heave, and pitch motion of the platform in these two cases in regular waves with $\mathrm{H}=4 \mathrm{~cm}$ and $\mathrm{T}=1.4 \mathrm{~s}$. Thus, the effect of a functional concentric WEC layout (with functional PTO system) on the motions of the platform can be seen in Fig. 11. The amplitudes of all three DoFs are reduced when WECs are attached to the platform. The average reduction in response amplitude is 30\% in the surge, $14 \%$ in the heave, and $80 \%$ in the pitch motion.

The main reason for this reduction is because of the radiation damping effect and restoring moment of the buoys that were attached to the platform with an equivalent PTO system (rotational damper) on the arm.

On the other hand, the heave motion of the buoys is studied in regular waves to derive the RAOs and compare them in different
Table 9

Variance of heaving velocity and acceleration of $B_{12}$.

\begin{tabular}{llllll}
\hline Sea States & \multicolumn{2}{l}{$\begin{array}{l}\text { Variance of Velocity }\left(\mathrm{mm}^{2} / \mathrm{s}^{4}\right) \times \\
\end{array}$} & & & \multicolumn{2}{l}{$\begin{array}{l}\text { Variance of Acceleration }\left(\mathrm{mm}^{2} /\right. \\
\left.\mathrm{s}^{6}\right) \times 10^{5}\end{array}$} & & & \\
\cline { 2 - 3 } \cline { 5 - 5 } \cline { 5 - 5 } & without damper & with damper & & without damper & with damper \\
\hline 2 & 5.05 & 2.39 & 6.49 & 2.84 \\
3 & 8.15 & 3.97 & 9.32 & 3.94 \\
4 & 11.14 & 5.84 & 10.08 & 4.62 \\
5 & 13.27 & 7.94 & 7.69 & 5.34 \\
6 & 19.38 & 10.07 & 12.96 & 6.23 \\
7 & 22.19 & 13.54 & 11.07 & 7.9 \\
\hline
\end{tabular}

scenarios. As is indicated in Table 4, two scenarios are considered for the cases "with WEC", WECs "without dampers" and WECs "with dampers". Fig. 12(a) shows the response amplitude of heave motion of buoy $B_{12}$ in regular waves $(H=1 \mathrm{~cm}$ and $T=3 \mathrm{~s})$ and Fig. 12(b) shows the RAOs of the $B_{12}$ in these two scenarios. The effect of damper on the RAO of buoy is not constant in different periods while the maximum decrease in RAO is 36\% in period of $0.8 \mathrm{~s}$ and there is a record of $16 \%$ increase in the period of $0.6 \mathrm{~s}$. Also, the RAO of the buoy, in $\mathrm{H}=2$ and $4 \mathrm{~cm}$ and $\mathrm{T}=1.4 \mathrm{~s}$, in "without damper" scenario is 1.2 , and in "with damper scenario" is 1.0 which are close to the values in $\mathrm{H}=1 \mathrm{~cm}$ in the same period.

Moreover, in Fig. 12(a), the difference between the peak amplitudes of heave is bigger than the difference between troughs. This is seen because the dampers that are used for these experiments are unidirectional (counterclockwise) and only act in upward directions. Also, the buoys are cone shape and their water surface area increases in the wave peaks and decreases in the wave troughs.

\subsection{Irregular wave tests}

Irregular wave tests of the platform are performed for the same cases and scenarios as the regular waves. Fig. 13 shows the motion response of the platform in "without WEC" case in the irregular waves in sea state $6(\mathrm{Hs}=12.04 \mathrm{~cm}, \mathrm{Tp}=1.59 \mathrm{~s})$. As revealed in this figure the floating platform has a considerable surge and heave motion and relatively small pitch.

Moreover, Fig. 14 (a) and (b) show that almost all energy of the pitch motion is located next to its natural frequency, even though the energetic band of the sea is located somewhere far from this

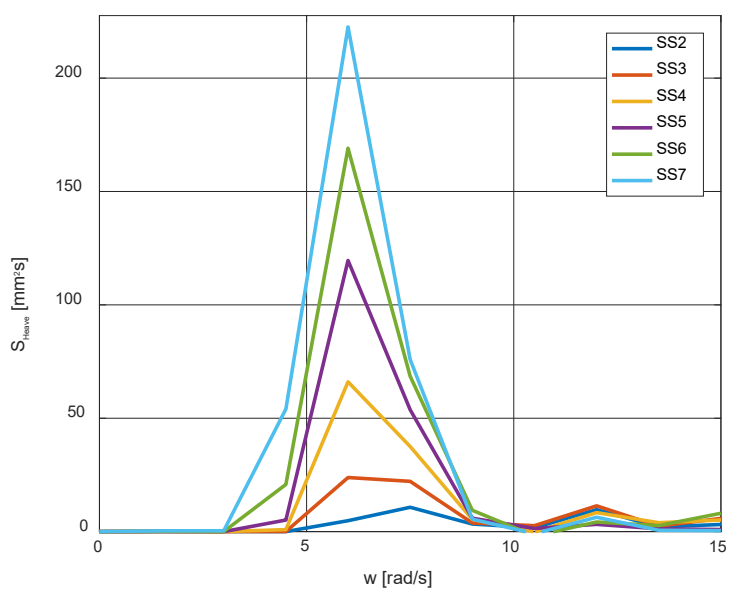

(a)

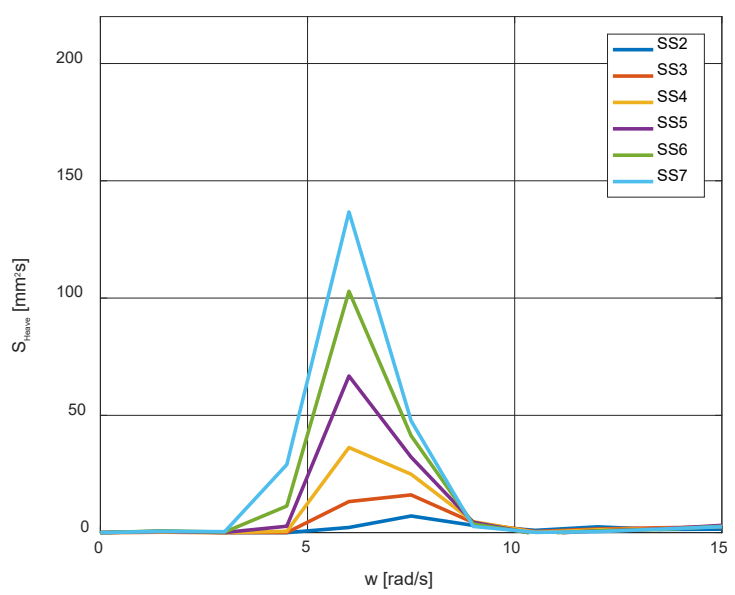

(b)

Fig. 17. Heave spectrum of $B_{12}$ in "without damper" (a) and "with damper" (b) scenarios. 

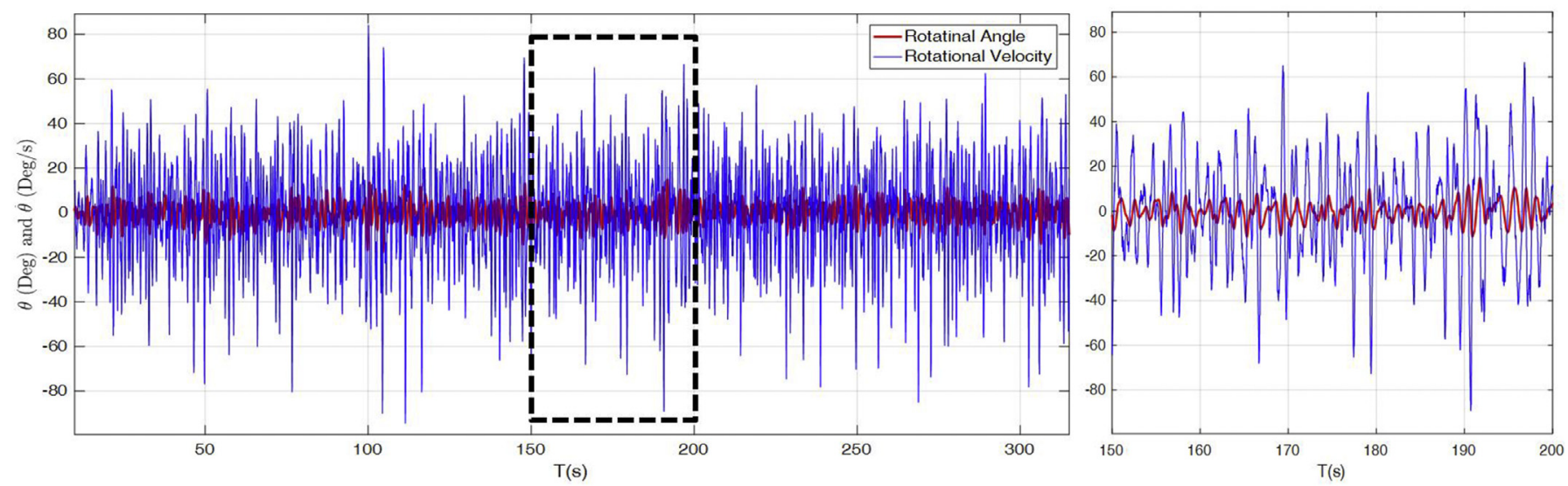

(a)
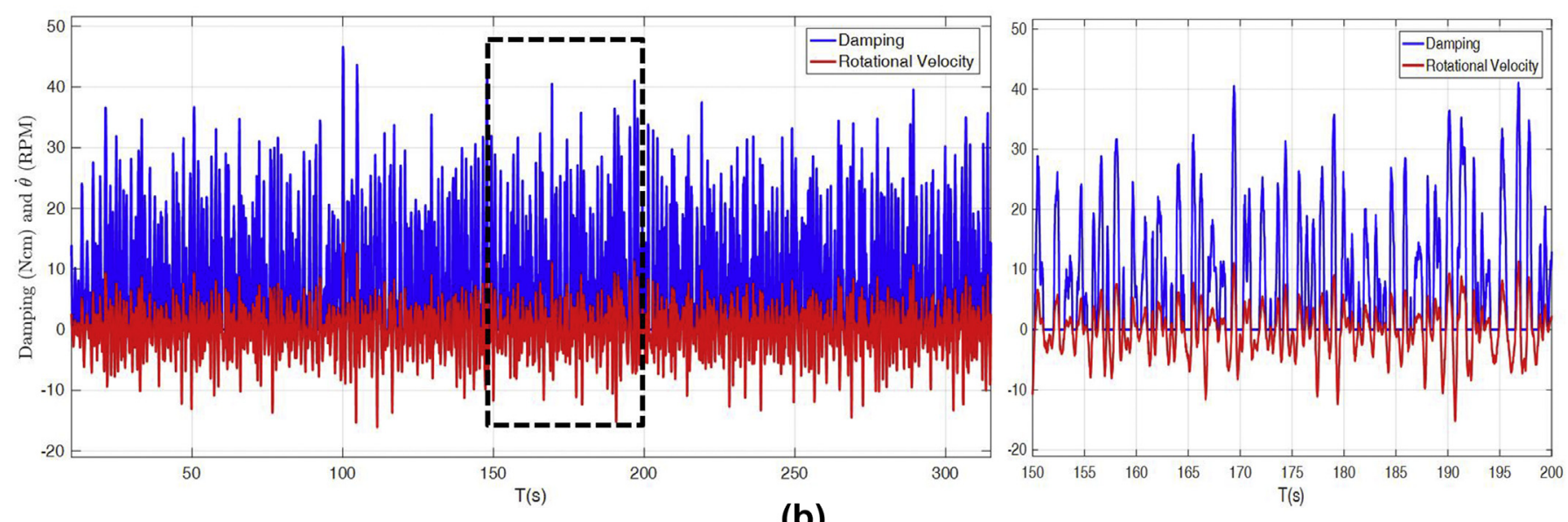

(b)

Fig. 18. Angular displacement and velocity of the arm (a) and rotational velocity of the $B_{12}$ and corresponding damping moments (b).

band. Moreover, the energy of the heave motion is evenly distributed between these bands. This is related to second-order wave-towave interactions that is very strong in the considered conditions.

As mentioned in the methodology section, the significant amplitudes of motion of heave and pitch are measured by two different methods. Table 6 shows the significant amplitudes of heave and pitch derived by both methods in different sea states. Also, the values are compared with numerical study of the floating platform carried out by Ref. [16]. As is seen, the obtained values from method 1 has a better agreement with the numerical result. So, the method 1 is used for the comparison of results in "without WEC" and "with WEC" cases.

Table 7 shows the significant amplitude of the heave and pitch motion of the platform in "with WEC" case in "with damper" scenario. The third and fifth columns of this table are showing the percentage of improvement in heave and pitch motion of the platform in the "with WEC" case compared with "without WEC" one. As presented in this table, the reductions in significant amplitude of heave and pitch motions are not constant and relatively increase by the sea states.

Table 7 also reveals that in sea state 2 the significant heave motion in "with-WEC" case is increased compared to "without WEC" one. In addition, the reduction in significant amplitude of pitch in sea state 4 is much higher than the trend in other sea states. The maximum reduction in heave and pitch response amplitudes are recorded in sea state 7 by $17.23 \%$ and $35.03 \%$, respectively. Meanwhile, Fig. 15(a) and (b) show the effects of the WEC array on the acceleration of the heave and pitch motions of the platform, respectively. After the installation of the WEC arrays on the platform, the acceleration of heave motion is increased, that means a faster response in heave direction are expected. Since the heave acceleration increases but heave amplitude decreases, it means that the peak frequency of response is moving to higher values at higher sea states. This can be verified in Fig. 14(a). Also, the acceleration of the pitch is decreased due to the restoring moment of the PTO system which is practically considered as a positive effect for the pitch motion. Especially, for a combined wind and wave platform, lower accelerations of pitch motion can decrease the harsh movements (less tension and fatigue stress on the mast and turbine blades) of the wind turbine on the top of the mast.

On the other hand, the irregular wave tests of buoys are done in order to monitor the relative motion of buoys and platform including the effects of dampers on the energy absorption of WECs. This data provides a broader vision on the interaction of each buoy and platform while the collective behavior of WECs on the motion of the platform is presented in the previous section. Also, the angular speed of the arms and PTO damping moments in various sea states can be extracted for improving the PTO system and definition of the control strategies. Fig. 16 shows the heave response of the buoy $\left(B_{12}\right)$ and deck $\left(C_{12}\right)$ in "with damper" scenario in sea state 6 . The significant amplitude of heave of the $B_{12}$ and $C_{12}$ in this sea state are $46.4 \mathrm{~mm}$ and $14.4 \mathrm{~mm}$, respectively. Moreover, Table 8 shows the comparison between the significant amplitude of the heave motion of $B_{12}$ in two different scenarios. It is seen that the 
heave significant amplitude of $\mathrm{B}_{12}$ is reduced after installation of dampers. Combining these results with the results in Table 7 shows that the PTO system is the critical link between the energy absorption of the WEC and stability of the platform.

Fig. 17(a) and (b) show the heave spectrum of the $B_{12}$, respectively for the situations "without damper" and "with damper". The heave spectrum is also an indicator for energy absorption of heaving point absorbers. As seen in Fig. 17, the damper absorbed the wave energy and affected the heave motion of buoy. But the amount of this energy absorption can be increased by optimizing the damping ratio of the PTO system which may also affect the stability of the floating platform.

Table 9 presents the variances of the heaving velocity and acceleration (calculated by Eqs. (3) and (4)) in the scenarios "with damper" and "without damper" in different sea states. The damper has a considerable effect on the heaving velocity and acceleration of the WEC. Thus, the damper as the equivalent PTO system, not only affects the heave amplitude of the WEC but also the velocity and acceleration of this motion. The damping coefficient of the PTO system is a function of the heaving velocity while the destructive forces on the joints (such as buckling) are related to the heave acceleration of point absorber. This means that, reducing the damping coefficient of the PTO in high sea states can make significant damages on the arm and joints.

Fig. 18(a) shows the angular displacement and velocity of the arm attached to $B_{12}$ in "with damper" scenario in sea state 7. The zoomed part in the right side of the figure shows that the average rotational velocity of the buoy $(\dot{\theta})$ is $28 \mathrm{deg} / \mathrm{s}$ which means $5.4 \mathrm{deg} / \mathrm{s}$ in full scale. Also, Fig. 18(b) shows the rotational velocity of the $\mathrm{B}_{12}$ in RPM and the corresponding damping moments $(\tau)$ dedicated to the rotational damper attached to its' arm. As mentioned before, the dampers only act counterclockwise. The maximum recorded damping moment is $0.4 \mathrm{Nm}$ which is equal to $212.6 \mathrm{kNm}$ in full scale.

\section{Conclusions}

The results of the free decay tests of the platform show that the eigen period of heave and pitch are reduced by adding the catenary mooring lines and installing the WECs. This reduction in pitch is considerably higher than the heave motion which is due to effect of WEC array on the hydrostatics and stability of the floating platform. Also, the restoring moment produced by WECs acts against the pitch motion and causes a faster response to the inclining moment.

The results of the regular wave tests are illustrating that a significant decrease is recorded in the amplitude of heave and pitch motions after adding the WEC array to the floating platform. This shows a significant advantage for adapting the floating concentric WEC arrays in offshore region. It should be indicated that, there is no control on applied dampers, used as the PTO system, while a controllable PTO system may increase the restoring effect of WECs on the platform.

On the other hand, the results of the regular wave tests of WEC arrays show that the RAO of buoy is reduced after installation of dampers on the arms. This reduction in RAO is due to the PTO damping effect on the energy absorption equation which has a direct relation with the amplitude of the WEC motions. It is seen that, the restoring moment generated by the motion of WECs cancels the pitch and heave moments of the platform in the wave while this phenomenon can have a negative effect on the energy absorption of the WEC, in absence of an active control system.

Moreover, the results of the irregular wave tests of the platform shows that the significant amplitude of heave and pitch in most of the sea states are reduced after installing WECs on the platform. The maximum reduction of heave and pitch motions are $19 \%$ and
$35 \%$, respectively. The results of the WEC motion in irregular waves show that the deployment of equivalent PTO system reduces the amplitude of heave motion of the buoy. In addition, the results show that with a variable damping PTO system and without any control on the damping coefficient, there is no control on the energy production of WEC and stability of the platform.

The inclusion of wind thrust simulation with the detailed study of Reynolds and Cauchy scales are envisaged for future works. Then, the impact of WECs on the platform shall be analyzed in presence of wind thrust which is a more realistic simulation for the combined platform.

\section{Declaration of competing interest}

There are no Conflicts of Interest.

\section{CRediT authorship contribution statement}

M. Kamarlouei: Methodology, Software, Formal analysis, Writing - original draft, Visualization. J.F. Gaspar: Methodology, Formal analysis, Writing - original draft, Visualization. M. Calvario: Methodology, Formal analysis, Writing - original draft. T.S. Hallak: Methodology, Formal analysis, Writing - original draft, Visualization. M.J.G.C. Mendes: Methodology, Writing - review \& editing. C. Guedes Soares: Methodology, Writing - review \& editing, Supervision.

\section{Acknowledgements}

This work was performed within the projects "Generic hydraulic Power Take-Off system for wave energy converters" and "Experimental simulation of oil-hydraulic Power Take-Off systems for Wave Energy Converters" funded by FCT, the Portuguese Foundation for Science and Technology (Fundação para a Ciência e Tecnologia) under contracts PTDC/EMS-SIS-1145/2014 and PTDC/EMEREN/29044/2017, respectively. The work contributes to the Strategic Research Plan of the Center for Marine Technology and Ocean Engineering (CENTEC), funded by FCT, under contract UID/Multi/ 00134/2013 - LISBOA-01-0145-FEDER-007629. The experimental work has received support from MaRINET 2, a Marine Renewable Infrastructure Network for Enhancing Technologies 2 under H2020-EU.1.4.1.2 "Integrating and opening existing national and regional research infrastructures of European Interest", project ID 731084.

\section{References}

[1] A. Babarit, J. Hals, M.J. Muliawan, A. Kurniawan, T. Moan, J. Krokstad, Numerical benchmarking study of a selection of wave energy converters, Renew. Energy 41 (2012) 44-63.

[2] Sea based [Online]. Available: http://www.seabased.com, 2018. (Accessed 11 October 2018).

[3] L.D. Mann, Application of ocean observations \& analysis: the CETO wave energy project, in: A. Schiller, G. Brassington (Eds.), Operational Oceanography in the 21st Century, Springer, Dordrecht, 2011, pp. 721-729.

[4] J. Weber, F. Mouwen, A. Parish, D. Robertson, Wavebob-research \& development network and tools in the context of systems engineering, in: Proc. EWTEC 2009 Eighth European Wave and Tidal Energy Conference, 2009, pp. $416-420$.

[5] Pontoon power technology [Online]. Available: http://www.pontoon.no/ Technology.html, 2018. (Accessed 11 October 2018).

[6] R.H. Hansen, M.M. Kramer, E. Vidal, Discrete displacement hydraulic power take-off system for the Wavestar wave energy converter, Energies 6 (2013) 4001-4044.

[7] Madjid Karimirad, Offshore Energy Structures: for Wind Power, Wave Energy and Hybrid Marine Platforms, Springer International Publishing, 2014, https:/| doi.org/10.1007/978-3-319-12175-8.

[8] C. Pérez-Collazo, D. Greaves, G. Iglesias, A review of combined wave and offshore wind energy, Renew. Sustain. Energy Rev. 42 (2015) 141-153.

[9] S. Ding, D. Han, Y. Zan, The application of wave energy converter in hybrid 
energy system, Open Mech. Eng. J. 8 (2014) 936-940.

[10] J. Sarmiento, A. Iturrioz, V. Ayllón, R. Guanche, IJ. Losada, Experimenta modelling of a multi-use floating platform for wave and wind energy harvesting, Ocean Eng. 173 (2019) 761-773.

[11] M.J. Legaz, D. Coronil, P. Mayorga, J. Fernández, Study of a hybrid renewable energy platform: W2Power, in: Proceedings of the ASME 2018 37th International Conference on Ocean, Offshore and Arctic Engineering OMAE 2018, Madrid, Spain, 2018.

[12] J.E. Hanssen, L. Margheritini, P. Mayorga, R. Hezari, K. O’ Sullivan, I. Martinez, A. Arriaga, I. Agos, J.H. Todalshaug, J. Steynor, D. Ingram, Design and performance validation of a hybrid offshore renewable energy platform: a path to cost-efficient development of deepwater marine energy resources, in: Tenth International Conference on Ecological Vehicles and Renewable Energies (EVER), 2015.

[13] Lee, H., Poguluri, S. K., Bae Y., H. Performance analysis of multiple wave energy converters placed on a floating platform in the frequency domain. Energies $11,406$.

[14] H. Zhu, C. Hu, A study on control of wave energy converter for motion suppression of semisubmersible, IFAC-PapersOnLine 49 (23) (2016) 380-385.

[15] J. Gaspar, M. Kamarlouei, M. Calvário, C. Guedes Soares, PTO concept for circular type WEC arrays, in: 2016 INORE North American Symposium, October 29 - November 2, Orono, Maine, 2016.

[16] J. Gaspar, M. Kamarlouei, M. Calvário, C. Guedes Soares, FOWT with controllable waterplane area, in: 2017 INORE North American Symposium, May $19-$ 22, Portland, Oregon, 2017.

[17] T.S. Hallak, J.F. Gaspar, M. Kamarlouei, M. Calvário, M.J. Mendes, F. Thiebaut C. Guedes Soares, "Numerical and experimental analysis of a hybrid windwave offshore floating platform's hull, in: Proc. ASME $37^{\text {th }}$ International Conference on Ocean, Offshore and Arctic Engineering, 2018. V11AT12A047.

[18] J.F. Gaspar, T.S. Hallak, C. Guedes Soares, Semi-submersible platform concep for a concentric array of wave energy converters, in: C. Guedes Soares (Ed.) Advances in Renewable Energies Offshore, Taylor \& Francis Group, London, 2018, pp. 307-314.

[19] M. Kamarlouei, J.F. Gaspar, M. Calvário, T.S. Hallak, C. Guedes Soares,
M.J.G.C. Mendes, F. Thiebaut, Prototyping and wave tank testing of a floating platform with point absorbers, in: C. Guedes Soares (Ed.), Advances in Renewable Energies Offshore, Taylor \& Francis Group, London, 2018, pp. $422-428$.

[20] J. Engström, M. Eriksson, M. Göteman, J. Isberg, M. Leijon, Performance of large arrays of point absorbing direct-driven wave energy converters, J. Appl. Phys. 114 (2013) 204502-204506

[21] P. Balitsky, G. Bacelli, J. Ringwood, Control-influenced layout optimization of arrays of wave energy converters,, in: Proc. ASME $33^{\text {rd }}$ International Conference on Offshore Mechanics and Artic Engineering, 2018. V09BT09A022.

[22] A. Sinha, D. Karmakar, C. Guedes Soares, Numerical modelling of an array of heaving point absorbers, in: C. Guedes Soares (Ed.), Renewable Energies Offshore, Taylor \& Francis Group, London, 2015, pp. 383-391.

[23] A. Sinha, D. Karmakar, J.F. Gaspar, M. Calvário, C. Guedes Soares, Time domain analysis of circular array of heaving point absorbers,, in: C. Guedes Soares, T.A. Santos (Eds.), Maritime Technology and Engineering III, Taylor \& Francis Group, London, 2016, pp. 1133-1140, https://doi.org/10.1201/b21890-152.

[24] S. Lefebvre, M. Collu, Preliminary design of a floating support structure for a 5 MW offshore wind turbine, Ocean Eng. 40 (2012) 15-26.

[25] S. Xiaojing, D. Huang, G. Wu, The current state of offshore wind energy technology development, Energy 41 (2012) 298-312.

[26] H. Bredmose, S.E. Larsen, D. Matha, A. Rettenmeier, E. Marino, L. Saettran, D2. 4: collation of offshore wind-wave dynamics, Marine Renewables Infrastructure Network (2012).

[27] ACE Controls Inc, FFD-25-FS-L-502, 2018 [Online]. Available: https://www. acecontrols.com/us/products/motion-control/rotary-dampers/ffd/ffd-fs-1/ffd25fs-1502.html. (Accessed 11 October 2018).

[28] S.K. Naqvi, Scale Model Experiments on Floating Offshore Wind Turbines, M. S. thesis, Worcester Polytechnic Institute, 2012.

[29] A.S. Zurkinden, F. Ferri, S. Beatty, J.P. Kofoed, M.M. Kramer, Non-linear numerical modeling and experimental testing of a point absorber wave energy converter, Ocean Eng. 78 (2014) 11-21.

[30] E. Uzunoglu, C. Guedes Soares, Automated processing of free roll decay experimental data, Ocean Eng. 102 (2015) 17-26. 